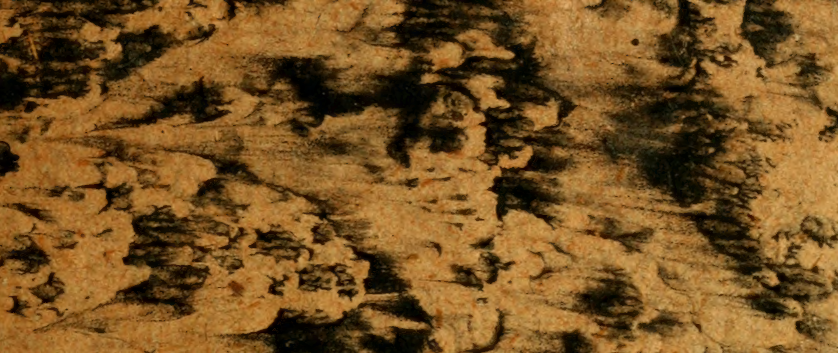

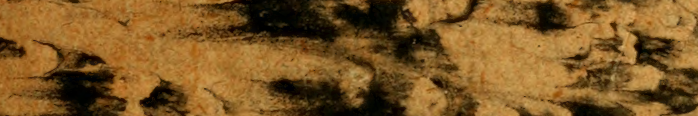

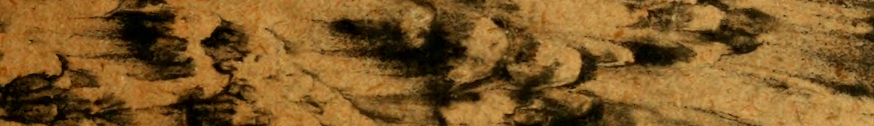
$3=-123+36$

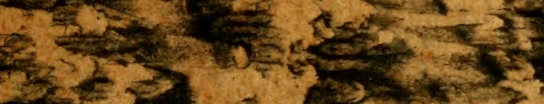
$x+2-2 x-2 x+31$

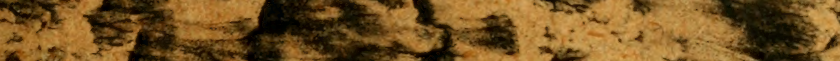

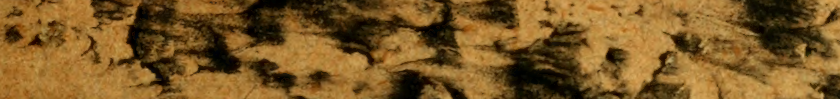

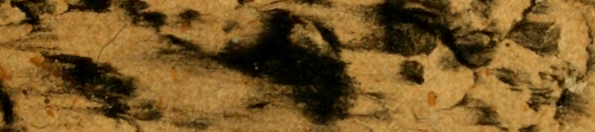

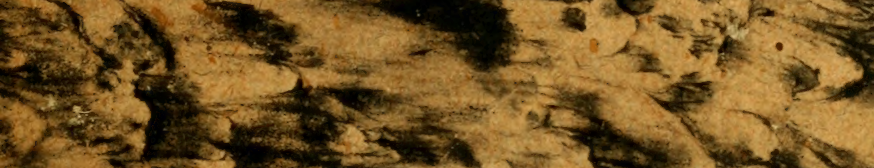

(1)

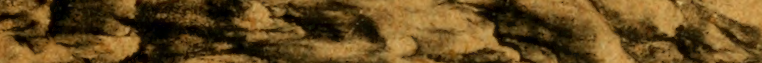

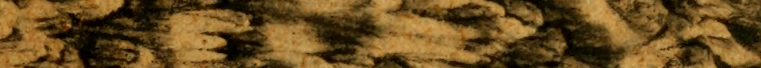

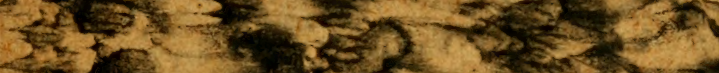
$5,72, \frac{25}{2}+2 x+3$ S$30-250$ The 37 2. $3 x^{2}-3 \times 1=$

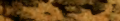

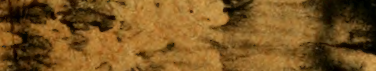
$8 x$

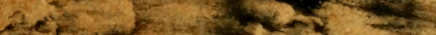
atemese 4) 


\title{
agibrary of the aftruseum
}

\section{COMPARATIVE ZOÖLOGY,}

\author{
AT HARVARD COLLEGE, CAMIBRIDGE, MASS.
}

founded by pribate subscription, in 1861.

\section{DR. L. DE KONINCK'S LIBRARY.}

$$
\text { No. } 10.58 \text {. }
$$


Colombo 1793

1058 

HATIVARO UINOSTTY

CAMBRIDGE. MA USA 
Vorficella polypima

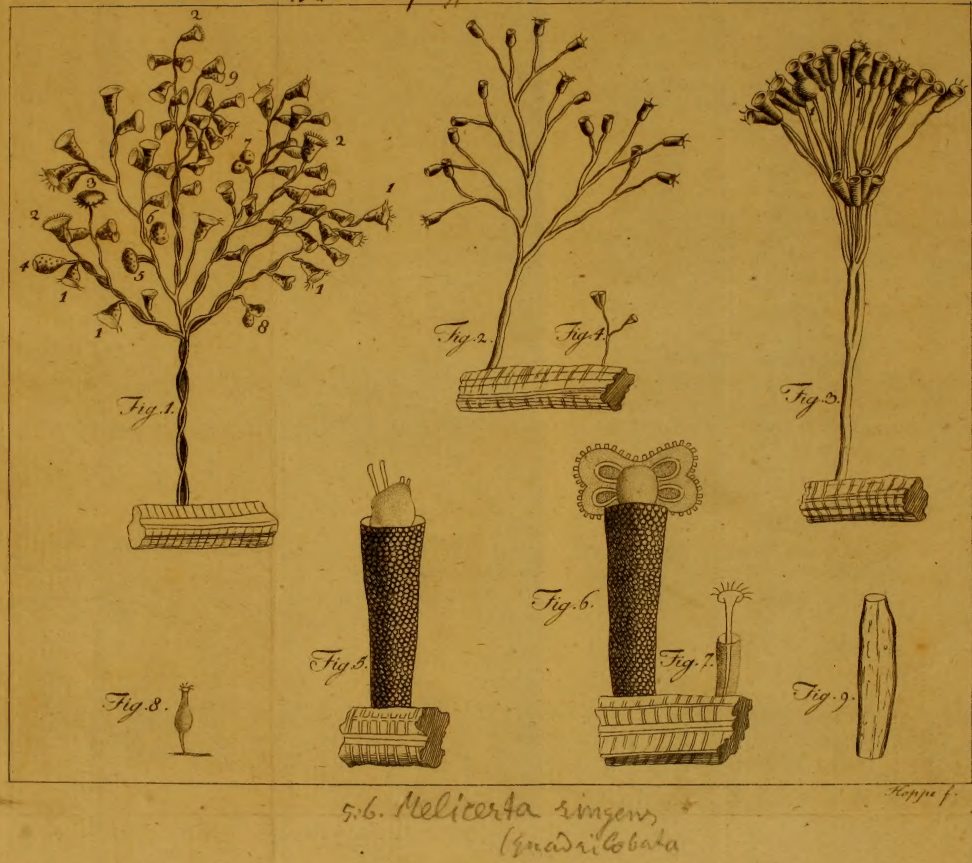


Michael Colombo's mikrofkopifche

\title{
Beobachtungen uiber
}

verfchiedene Arten

ron

Polypen des füfsen Waffers

\author{
und über \\ die Räderthiere.
}

In einem Briefe

an

D. J o h a n n a r d i; Arź zu Vazzola.

A us dem Italienifchen. Mit einer Kupfertafel. He

$$
\text { Leipzig, } 199 \text {. }
$$

In der Müllerifchen Buchhandlung. 


\section{a}

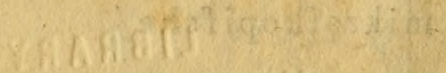

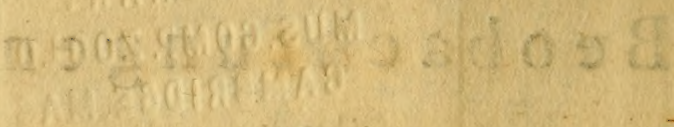

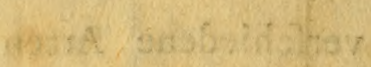

$$
\begin{aligned}
& 2016
\end{aligned}
$$

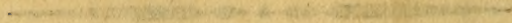

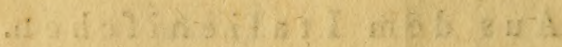

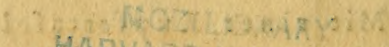

HARVARD UNWET ITY

CAMBRIDGE. MA. UR'

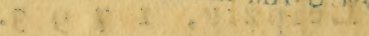

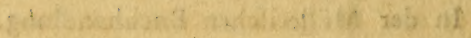



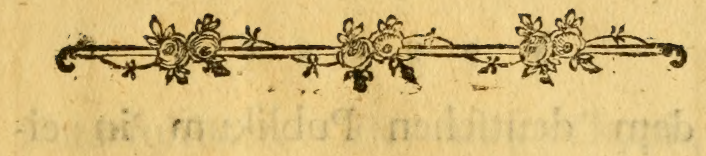

(1)

\section{Vor r e d e des}

U e b e r fetzers.

Diefe kleine Schrift *) des Herrn Colombo, eines mit Recht gefchätzten Naturforfchers, verdiente

\section{A 2 \\ dem}

*) Offervazioni microfcopiche intorno a varie fpezie di polipi di acqua dolce, ed intorno ai rotiferi, dirette dal Sig. Michele Colombo al Sig. D. Gro, Nardi Medico alla Vazzola. 
$V \circ x \quad x$ e d e.

dem deutfchen Publikum in einer Ueberfetzung vorgelegt zu werden. Sie ift in einer italienifchen Zeitfchrift enthalten, die wohl nur wenigen deutrchen Gelehrten zu Geficht kommen dürfte *). Des Verfaffers Bemerkungen über die Polypen, diefe fo merkwürdige Thiergattung, tragen unverkennbare Spuren eines aufmerkfamen und geübten Beobachtungsgeiftes an fich. Sind fie auch nicht alle neu, und zum Theil nur neue Beftitigungen fchon bekannter Thatfachen, fo verdienen fie doch darum nicht weniger den Dank der

$\mathrm{Na}$.

*) Sie findet fich im Giornale per fervire alla ftoria ragionata della medicina di quefto fecolo. Tomo IV. Venezia, 1787. pagg. i. ff. 41, f, 81. I. 125. ก. 16 . $f$ 


\section{V $\circ$ i $\quad$ r c d e.}

Naturforfcher. Bey mikrorkopifchen Gegenftänden, wo auch der fcharffichtigfte und geduldigfte Beobachter fo leicht getaufcht werden kann, künnen die Beobachtungen nicht genug wiecterholt und vervielfaltigt werden.

Unter den Bemerkungen, welche Herr Colombo beylaufig einfreut, find vorzüglich feine Gedanken über die Mittel glieder der Naturkette zwifchen dem Thier-und Pflanzenreiche und über den Uebergang aus dem einen Reiche ins andere der Aufmerkfamkeit der Naturforfcher würdig. Die Erinnerungen, welche er gegen DauBENTON's Methode, diefe Mirtelglieder ausfindig zu machen, beybringt, find

$$
\text { A. ge- }
$$




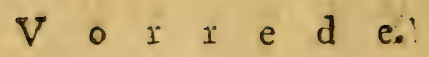

gegründet, und der Weg, welchen er dafür einfchlägt, fcheint einzig und allein zum Ziele zu führen.

Es ift zu wünfchen, dafs der Verfaffer und fein Freund, NARDI, von deffen Scharffichtigkeit er fich fo viel verfpricht, Luft und Mufse haben mögen, den Wundern der mikrofkopifchen Schöpfung, wo gewifs das meifte zu entdecken noch übrig ift, ferner nachzufpüren. 


\section{Mikrofkopifche \\ B e o b a c h u n g n über}

verfchiedene Arten

ron

Polypen des füfsen Waffers

und über

die Räderthicre. 


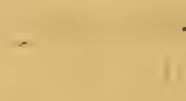

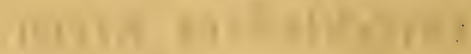

$\because+2-47 \div 0=1$

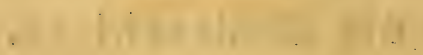




\section{Miknofkopifche}

$B$ e o b a cht u n g n über verfchiedene Arten

von

Polypen des fürsen Waffers und über die $R$ äderthiere.

Theurefter Freund!

Fudlich gebe ich Ihnen von den Beob: achtungen Nachricht, welche ich, wie Sie wiffen, über einige von den vielen Thierarten, die fich $z$ wifchen den Wurzeln der Meerlinfen aufzuhalten pflegen, angeftellt habe. Ich habe mich hauptfächlich mit der Unterfuchung der baumformigen Thierchen *) befchäftigt, die fchon von SPAL-

$$
\text { A 5. LAN= }
$$

*) Alberetti animali. 
LANZANI befchrieben worden find ). Durch die Befchreibung, welche uns diefer Naturforfcher davon gibt, war ich eigentlich bewogen worden, die Wurzeln der Meerlinfen zu unterfuchen, um mich an dem angenehmen Schaufpiele, welches diefe fonderbaren Thierchen darftellen, gleichfalls zu vergnügen.

Weil fich in der Meerlinfe, welche SpALLANZANI unterfuchte, nur fehr wenig folche Thierchen fanden, war es ihm unmöglich, feine Beobachtungen darüber fo oft zu wiedertiohlen, als er wahricheinlich gethan haben würde, wenn ihm deren mehr zu Theil geworden wären. Man darf fich daher nicht wundern, dafs ihm einige Eigenheiten diefer Thierchen unbekannt geblieben find, die feinem Scharffinne gewifs nicht entwifcht feyn würden, wenn er mehr $\mathrm{Ge}$ legenheit, fie zu beobachten, gehabt hätte. Anfangs glaubte ich auch nicht mehr bemerken zu können, als ein fo vortreflicher Beobachter zu fehen im Stande gewefen war; allein die grofse Menge diefer Thierchen, welche ich in einigen Waffergräben unferer Ge-

*) Man fehe fein vortrefliches Werk: Opuscoli di Fifica animale e vegetabile. 
Gegend zu finden das Glück hatte, machte es mir möglich, meine Beobachtungen nach Gefallen zu wiederhohlen und abzuändern, fo dafs ich zuletzt eines und das andere entdeckte, was mir neu und von andern Naturforfchern noch nicht beobachtet zu feyn fchien.

Ohne mich darum zu bekiummern, was man von diefen Thierchen bisher gewufst oder nicht gewufst hat, will ich fie Ihnen befchreiben, fo wie ich fie beobachtet habe. Die Wiederhohlung fchon bekannter Sachen ift nicht immer unnütz, wenn nur das, was erzählt wird, fich auf eigne Beobachtungen gründet. Stimmen mehrere Beobachter in ihren Beobachtungen überein, fo können wir uns von der Wahrheit derfelben defto mehr überzeugen.

Die Räderthiere mit Futteralen * * aus genommen, von welchen ich Ihnen eines und das andere werde mittheilen können, erwarten Sie von mir ja keine weitläuftige $B e-$ fchreibung diefer Gefchöpfe. Da ich fre nux gelegentlich beobachtet habe, fo wєifs ich von ihnen wenig mehr, als dafs fie exiflixen. Was die befondern Umftände ihres Oelko-

†) Rotiferi ad aftuccio. 
Oekonomie betriff, fo hoffe ich von Ihnen in der Zukunft darüber belehrt zu werden. Sie befitzen ein trefliches Mikrofkop; Sie können mit diefem Inftrumente wichtige Entdeckungen machien, und der Naturgefchichte keine geringen Dienfte leiften.

\section{I.}

Man lege in ein etwas geräumiges Uhrglas einige Meerlinfenwurzeln, und giefse ein wenig Waller darauf. Unterfucht man hierauf die Wurzeln mit einer guten Lupe, fo wird man an einigen zuweilen ein weifslichtes Fleckchen gewahr werden, welches, wie man fehr bald fehen wird, aus einigen Reihen von Punkten befteht. Man bewege das Glas, fo wird diefer Fleck kleiner werden, und fich der Wurzel der Meerlinfe rähern. Hört die Errchütterung wieder auf, fo wird er fich wieder etwas entfernen, und, wie vorher, ausbreiten. Um dergleichen Flecke leichter gewahr zu werden, darf man fich nur einem Fenfter nähern; nur mufs man nirht allzunahe an daffelbe treten, denn zu viel Licht fchadet eben fo gut, als eine zu fchwache Erleuchtung.

Man bringe das Fleckchen unter das Mikrofkop, und es werden fich dem Auge ein oder 
oder mehrere arlige Büumchen *) darftellen. Während dais inan cen Stamm, der an der Wurzel-der Meerlinfe feit fteht, und mel rere Aefte trägt, und die Aefte, die fich immerin kleinere Aeftchen theilen, unterfucht, ziehen fich ein oder mehrere Aeffe in einem Augen- blick zufammen. Alle ihre Glocken fallen zufammen, und ziehen fich nach dem Stamm hin; allein fehr bald darauf dehnen fich die Aefte wieder aus, die Glocken entfernen fich wieder von einander, und alles kehrt a: feinen vorigen Ort zurück.

Nicht nur die Glocken und die Aefte, fondern auch der Stamm diefes mikrofkopifchen Pflänzchens befitzen das Vermögen, fich nach Willkuihr zu bewegen, zufammen zu ziehen und auszudehnen. Wenn alfoeinige Philofophen die Animalität den Pflanzen haben einräumen wollen, fo ift diefes Pfänzchen vorzüglich berechtigt, hierauf Anfpruch zu machen. Es if ganz eigentlich ein Thier, oder vielmehr ein Aggregat thierifcher Wefen, deren jedes, wie wir in der Folge fehen werden, für fich und von den andern unabhängig lebt.

Die 
Die gedachte Zufammenziehung gefchieht mit einer fo grofsen Schnelligkeit, dafs das Auge gar nicht unterfcheiden kann, wie fie vor fich geht; allein weil darauf die Aeftchen fowohl als die Glocken ihre vorige Stellung langfamer wieder annehmen, fo zeigt fich damn deutlich, dafs fich die Stiele und Aefte nach verfchiedenen Richtungen zufammen gelegt und dadurch verkürzt hatten. Im Augenblick der Zufammenziehung verfchliefsen die Glocken ihre weitefte Mündung; fie öffnen fie wieder allmählich, während dafs fich die Aefte und Stiele wieder ausdehnen; die völlige Oeffnung pflegt aber nicht eher zu erfolgen, als bis fich diefe vollkommen ausgedehnt haben. In diefem Augenblicke fcheinen die Glocken ihre Lippe etwas umzufchlagen, und auf diefe Weife wird ihr vorderes Ende etwas dick.

Die Aefte ziehen fich gewöhnlich, befonders wenn der Baum fehr grofs ift, nicht alle auf einmal zufammen, fondern bald diefer, bald jener; jedoch zuweilen fallen fie alle zugleich zufammen, und die Glocken des ganzen Baums kommen auf die Meerlinfenwurzel, welche denfelben trägt, zu liegen.

Wenn dergleichen Zufammenziehungen nicht 
nicht von felbft entftehen, fo reicht eine kleine Errchütterung des Glafes zu, diefelben entweder in dem ganzen Pfänzchen oder wenigftens in einigen Aeften hervorzubringen.

Man giefse in das Glas Waffer aus einem Graben, und man wird die kleinen Körperchen, womit daffelbe angefülit ift, in einer immerwährenden Bewegung fehen. Wenn dergleichen Körperchen fich der Mündung der Glocken nähern, fo werden fie dahin gezogen, und in einen kleinen Strudel. geriffen, in welchem fie fich fchnell herumdrehen. Man verfolge fie mit dem Auge, fo wird man bald gewahr werden, dafs einige derfelben in die Mündung der Glocke hinein gehen, indefs der gröfste Theil, gleichfam von der Glocke zurückgeftofsen, am Rande derfelben vorbeygeht, aus dem Strudel entwifcht, und fich hierauf wieder langtam bewegt, bis er in den Strudel einer andern Glocke geräth. Der Strudel hört auf, 'fo oft die Glocken ihre Mündung verfchilieffen, und zuweilen auch, indem diefelben noch geöffnet find.

Diefe Strudel werden durch gewiffe kleine Spitzen, womit die Mündung der Glocken verfehen ift, und vielleicht auch durch die Lippe der Glocken felbft hervorgebracht. 
Diefe Spitzen laffen fich nur mit der grölsten Schwierigkeit deutlich exkennen. Mit der Unterfuchung derfelben habe ich mich am meiften und forgfältigften befchäftigt. Meine Refultate find folgende.

i. In vielen Glocken zeigen fich einige Spitzen, und zwar meiftentheils nach den Seiten der Lippe zu *).

2. In vielen laffen fich keine (wenigftens nicht mit meinen Linfengläfern), nicht einmahl an den Seiten der Mïindung, entdecken.

3. In einigen zeigen fich welche auch am obern und untern Theile der Mündung.

4. In einigen andern fieht man welche fehr fchnell zum Vorfchein kommen und wieder verfchwinden.

5. Statt dafs fie in allen diefen Fällen fich fehr fparfam zeigen, und gewöhnlich unter einander divergiren, find fie andremahl, wiewohl nur felten, fehr zahlreich, insge. famint der Achfe der Glocke parallel, nach Art einer Krone um den Rand herum gebrdnet ${ }^{* * *}$ ), und in einer kleinen, aber fchnel-

$$
\begin{aligned}
& \text { 4) Fig. I. (1). } \\
& \text { *) Fig. I. (2). }
\end{aligned}
$$


fchnellen Bewegurig: Alsdann mufs man das Geficht fehr gut bewaffinen, um fie deuilich fehen zu können; fonft glaubt man weiter nichts als ein geringes Zittern in der Mündung der Glocke gewahr zu werden.

Dafs unfere Glöckchen mit fo vielen Spitzchen wirklith verfehen find, läfst fich nicht bezweifeln, da diefelben an der Mündung einiger Glocken gefehen worclen. Woher mag es aber wohl kommen; dafs dergleichen Spitzen in den meiften Glocken fich entweder gar nicht zeigen, oder fichtbar werden, und wieder verfchwinden, und dafs fie, auch wenn fie fichtbar find, doch in fo geringer Anzahl zum Vorfchein kommen. Vielleicht können fie die Thierchen, wie die Wefpen ihren Stachel, oder wie die Schnecken ihre Hörner, nach Willkühr ausdehnen und wieder einziehen; vielleicht waren aber auch meine Linfen, fo vortreflich fie auch find, doch nicht fo gut, als fie bey fo feinen Beobacttungen feyn müfsten; vielleicht ward ich alfo die Spitzchen nur dann gewahr, wenn fe fich in einer für das Auge vorzüglich günftigcri Lage befanden. Zwey Griinde beftärken mich in diefer Vermuthung nicht wenig. Erftens gedenkt Herr Srallanzani, ein fo aufmerkfamer und genauer Beobachter, der 
88

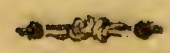

Verfchiedenheiten, welche ich bey den Spitzen bemerkt habe, mit keinem Worte. Zweytens verträgt fich der Umftand, dafs die Spitzen eher an den Seiten, als in den andern Stellen des Randes zum Vorfchein kommen, nicht mit der Struktur deffelben; denn da die Mündung zirkelförmig ift, fo ift es ein blofser Zufall, wenn fich eher ein Theil derfelben, als ein anderer, an den Seiten der Glocke zeigt. Wir wollen annehmen, dafs die Spitzen wegen ihrer grofsen Feinheit und Durchfichtigkeit unfichtbar find, wenn nicht einige Umftände dazu beytragen, diefelben merklicher zu machen, fo fliefst aus diefer Vorausfetzung folgendes.

I. Ich werde fie eher an den Seiten, als in irgend einer andern Stelle des Randes gewahr werden mi:ffen; denn da fie dort in Beziehung auf das Auge unmittelbar unter einander liegen, fo bilden fie gleichfam eine Gruppe, die für eine einzige etwas dicke Spitze gehalten werden kann. U'eberdiefs wird dafelbft ihre Durchfichigkeit vermindert, weil diefe Gruppe dem Durchgange des Lichtes nothwendig mehr Widerftand, als eine einzige Spitze, leiften mufs. Folglich entzieht fie dafelbft dem Auge weder ihre Feinheit, noch ihre Durchfichtigkeit. 
2. Ich werde fie nicht einmal dort gewahr werden können, fo oft fie dermaisen divergiren, dafs felbft diejenigen, welche fich an den Seiten des Randes befinden, einzeln, nicht gruppenartig verbunden, in das Auge fallen.

3. Ich werde fie auch an jeder andern Stelle der Mündung erblicken, fo oft als die Thierchen einige davon mit einander verbinden.

4. Sie werden zum Vorfchein kommen, und wieder verfchwinden, wenn die Thierchen einige vereinigen, und hierauf wieder von einander trennen.

5. Wenn endlich die Thierchen fie alle parallel halten, und mit grofser Gefchwindigkeit bewegen, fo werden fie, da fie vermöge diefer Bewegung ein zufammenhängendes Ganzes darftellen, uberall am Rande fichtbar; nur muis man dann das Auge wohl bewaffnen, um ihr leichtes Zittern deutlich gewahr zu werden.

Der einzige Umitand, welchen ich mit diefer Vorausfetzung nicht $z u$ vereinigen weifs, ift, dafs dann, während die Thierchen die Mündung gefchloffen halten, die Spitzen alle zufammen vereinigt feyn, folg- 
lich am deutlichften in die Augen fallen miifsten; was doch keinesweges der Fall iff. Ich weifs daher wirklich nicht, was ich von diefen Spitzen glauben foll *).

Srallanzani glaubt, dafs die Mündung der Glocke fich in der Mitte in ein kleines Loch endigt. $\mathrm{Da}$ immer einige Glocken aufgerichtet ftehen, fo kann man die innere Struktur derfelben fehr leicht unterfuchen. Man wird daher leicht glauben, dafs ich diefem Loche fehr aufmerkfam nachgefpürt habe. Zuweilen habe ich es gleichfalls zu fehen geglaubt; allein die meiften Mahle habe ich es vergebens gefucht.

Die Durchfichtigkeit der Glocken lässt uns inwendig viele kleine Körner gewahr werden. In einigen Glocken gibt es deren eine gröfstre, in andern eine geringere An$z a h l$, und eine und diefelbe Glocke befitzt nicht immer gleich viel. Vielleicht find diefs Theilchen der genoffenen Nahrung, die wegen der grofsen Durchfichtigkeit der Behältniffe, wo fie fich finden, fichtbar find. Meine Muthmafsung gründet fich hauptfầchlich darauf, dafs ich deren immer weit weniger gefehen habe, fo oft als die Glocken

†) (Man fehe unten die Nach Chsift.) 
im Glare einige Zeit lang in einerley Waffer gewefen waren. Die Anfangs reichliche Nahrung mufste mit der Zeit nothwendig fehr abnehmen, als die Thierchen fchon einen guten Theil davon verzehrt hatten.

Die Stiele der Glocken, die Zweige und der Stamm felbft fcheinen aus mehrern Fäden gleichfam zufammen gedreht, die, wenn fie fich ausgedehnt haben, hier und da etwas gekrümmt find.

Sehr oft fieht man am Bäumchen einige Glocken ihre gew öhnliche Geftalt verlieren, und eine andere ganz verfchiedene annehmen. Das Thierchen fchliefst allmählich die Mündung, und am hintern Ende zeigt fich eine Krone von Fädchen *), die vorher nicht fichtbar waren. Es bewegt fie Anfangs langfain, wird zu gleicher Zeit kürzer und dicker, und nimmt gleichfam die Geftalt einer Zwiebel an. Die Bewegung der Fädchen wird immer fchneller. Mittlerweile verlängert fich das Thierchen wiederum unmerklich, bewegt die Fädchen immer gefchwinder, gerïth felbft in Bewegung, dreht fich einige Mahl um feinen Stiel, und geht

$B_{3}$ end- 
endlich davon los. Alles diefs gefchieht un. gefähr in einer halben Stunde *).

Man mufs die gedachten Fädchen nicht mit den Spitzchen verwechfeln, die fich an der Mündung der Glocke zu zeigen pflegen. Statt dafs die Spitzchen, felbft wenn fie bewegt werden, immer gerade bleiben, find die Füdchen gleichfam fchlangenförmig gewunden. Ueberdiefs befinden fich die Fädchen, von denen ich hier rede, gedachter Mafsen nicht am vordern, fondern am hintern Theile des Thieres. Der überzeugendfte Beweis vom Unterfchiede der Fädchen und der Spitzchen ift, dafs das Thierchen zuweilen die Fädchen hinten zubewegen anfärgt, wenn an der noch nicht völlig verfchlolfenen Mündung die Spitzchen immer noch fichtbar find. Freylich ift diefs ein fehr feltenes Phänomen. Man ftöfst nicht leicht auf Glocken, die fogleich ihre gewöhnliche Geitalt zu verlieren, und die Fädchen auszuftrecken anfangen. Ich hatte dergleichen Thierchen fchon lange Zeit und ziemlich fleifsig beobachtet, ehe ich Gloeken gewahr werden konnte, die zu gleicher

*) (Man fehe unten die Nachfehrift.) 
oher Zeit vorn Spitzchen und hinten Fädchen tatten.

Was werden wir aber fagen, wenn wir, nachdem fich das Thierchen abgelöfst hat, Tehen werden, dafs eben der Theil, der vorher das hintere Ende ausmachte, nunmehr das vordere Ende ift, und die Fädchen, die zuvor von den Spitzchen verfchieden waren, die Spitzchen der neuen Mündung getiorden find? Diefs fchien mir in der That der Fall zu feyn, fo oft ich diefe fonderbare Ablöfung der Glocken beobachtete. Inzwifchen find dergleichen mikrofkopifche Beobachtungen fo fchwer anzuftellen, und überdiefs kann man fich bey Gegenftänden, mit denen man noch nicht recht vertraut ift, fo leicht irren, dafs ich fehr wünfche, es möchten fich andere Beobachter die Mühie geben, diefer fonderbaren Verwandlung des Mundes in den Hintertheil und des Hintertheils in den Mund, fie mag nun wahr oder nur fcheinbar feyn, mit aller Scharffichtigkeit nachzuforfchen.

Hat fich das Thierchen abgefondert, fo unterfcheidet es fich der Form nach nicht fehr von einem Eimer, aufier dafs es etwas länglicher ift. Wenn es fchwimmt, fo hat es die Mündung gewöhnlich unten, zuwei- 
len aber auch oben; es kommt und gelit, und dreht fich unzählige Mahl. Von Zeit zu Zeit ruht es auf der Meerlinfenwurzel, oder auf dem Bäumchen felbit, von welchem es los gegangen ift; es geht um die Wurzel herum, oder längs derfelben hin, oder es bewegt fich auf dem Boden des Glafes, und die Spitzchen dienen ihm anftatt der Füfse. Es fteht einige Zeit lang unbeweglich, fchweift dann wieder umher, und bleibt $z u-$ letzt entweder auf der Meerlinfenwurzel, oder auch auf dem Boden des Glafes, inden es nichts weiter thut, als dafs es die Mündung ein wenig erweitert und zufammenzieht.

\section{Einige Stunden darauf fieht man am hin-} tern Theile einen kleinen Stiel zum Vorfchein kommen. Mit demfelben befeftigt fich das Thierchen an dem Orte, wo es feine Wohnung auffchlagen will. Diefer Stiel verlängext fich unmerklich immer mehr und mehr, bis er fünf bis fechs Mahl grölser, als die Achife der Glocke, geworden ift. Er ift der Länge nach aus mehrern Fäden obgedachter Marsen gleichfam zufammen gewebt. Man braucht das Thierchen nur von Zeit zu Zeit zu betrachten, fo wird man gewahr, dafs fich ein neues Bäumchen bildet. Die Glocke theilt fich in zwey Glocken, 
die zwey Glocken in vicr, dann in acht u. f. w. Die zwey erften Tage über bleiben die Glocken nahe bey einander, und bilden noch kein Bäumchen; man fieht weiter nichts als eine Gruppe von Glocken, die, jede mit einem eignen Stiele, an einem gemeinfchaftlichen Stamme befeftigt find. Allein diefe: Stamm wird hernach ein wenig ftärker; die Stiele verlängern fich; es bilden fich vermittelft der neuen Theilungen der Glocken neue Stiele auf den alten; es entfpringen daraus verfchiedene Aefte, und in fünf bis fechs $T_{2}$ gen hat man bey warmer Witterung einer fchönen Baum.

Die Theilung der Glocken anlangend, kommen meine und SPallanzani's Beo: bachtungen nicht mit einander überein. Unter die Kẹnzeichen, woran fich die baumförmigen Thierchen von den Straufspolypen *) unterfcheiden laffen follen, zählt SpALLANzANI auch den Umftand, dafs die gedachten Polypen, bevor fie fich theilen, die glockenförmige Geftalt verlieren. Nach Sp.1LLANZANI verlieren alfo die Thierchen unferer Bäumchen vor der Theilung diefelbe nicht; fonft würden fie hierin nicht von den

\section{B 5}

Straufs:

a) Polipi a fiocco. 
Straufspolypen verf́hieden feyn. Allein fo oft ich auch die Theilung der Glocken an unfern Bäumchen beobachtet habe, fo habe ich fie doch nicht ein einziges Mahl ohne Aenderung der Glockenform vor fich gehen fehen. Alle Thierchen, welche ich während diefer Operation habe beobachten können, haben fich auf folgende Weife getheilt.

Bevor die Theilung angeht, verliert das Thierchen die glockenfö mige Geftalt, und wird einer etwas länglichen Birn ähnlich *). Am vordern Ende diefer Birn bemerkt man gleich Anfangs ein immerwährendes Aufwallen. Die Birn wird allmählich kürzer, und zuletzt vollkommen kugelrund. Das Aufwallen dauert immer fort, die Seiten fchwellen an, und das Thier wird in die Quer gröfser, als in die Länge ***). Der vordere Theil nähert fich dem hintern immex mehr, und in der Mitte des vordern Theils fängt eine kleine Krümmung nach hinten zu fichtbar zu werden an ${ }^{*}$ ). An dem übrigen Theil des Körpers zeigt fich noch keine

Spur

\author{
*) Fig I. (4.) \\ *) Fig. I. (5.) \\ ****; Fig. I. (6.)
}


Spur einer Theilung. Diefs gefchieht erft einige Minuten darauf, und nun bekommt man bald zwey kleine, an einancer fto fsende Kugeln *) zu fehen, die hinten unmerklich länger werden, und die Geftalt zweyer kleiner an einerley Stiel befeftigter Birnen annehmen *). Beobachtet man fie genau, fo wird man in beyden an einer gewiffen Stelle ein anhaltendes Zittern gewahr werden: dafelbft kann man fchon eine kleine Lippe erkennen, die fich immer mehr und mehr öfnet; diefe Lippe bekommt Spitzen, die mit grofser Schnelligkeit bewegt werden, und endlich zeigen fich zwey Glöckchen, die nur noch etwas kleiner, als die andern, find. In weniger ais einer Stunde geht diefe ganze Operation von Statten, während welcher das Thier keinen Strudel erregt.

Die zwey Glöckchen find alsdann an einen und denfelben Stiel befeftigt. Um fie alle beyde zu erkennen, mufs man fie ge rade im Geficht haben. Zuweilen ftellen fie fich dem Auge fo dar, dafs die eine unter der andern liegt, und man nur eine erblickt; zuweilen fo, dafs man von der un-

tern

\section{*) Fig. 1. (7.) \\ *) Fig, I. (t.)}




\section{8}

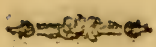

tern nur einen Theil gewahr wird, indefs der andere Theil vom obern Glöckchen bedeckt bleibt. Dann glaubt man eine einzige Glocke zu fehen, die etwas breiter, als die andern, und oben der Länge nach gezeichnet ift. Man könnte fie leicht für eine Glocke halten, welche fich zu theilen anfïngt, und diefs kann vielleicht Veranlaffung gegeben haben, zu glauben, dafs die Glocken der Bäumchen, während dafs fie fich theilen, ihre gewöhnliche Geftalt behalten. Ich bin felbft in diefen Irrthum Ar. fangs mehr als einmal gerathen. Man erfchüttere das Glas etwas, damit fich das Bäumchen zufammen ziehe, und beobachte den Ort aufmerkfam, wo das gedachter $\mathrm{Ma-}$ fsen gefurchte Glöckchen zum Vorfchein gekommen ift; weil die Glocken, wenn fich die Aefte und Stiele wieder ausftrecken, fich etwas herum zu drehen pflegen, fo wird man beyde an einander ftofsende Glöckchen deutlich gewahr werden, die fodann wieder ihre erfte Lage einnehmen, und eine einzige der Länge nach gefurchte Glocke zu feyn fcheinen.

Indem fich die Glocke theilt, theilt fich der Stiel, an welchem fie befeltigt ift, nicht mit. Die Glöckchen entwickeln nach voll- 
brachter Theilung ihre eignen Stiele auf dem Baume, fo wie fie diefelben entwickeln, wenn fie rom Baume los gehen, und fich anderswo feft fetzen; und auf diefe Weife bilden fich die neuen Stiele. Herr Spallanzanr hatte lierüber, wie er felbft fagt, nicht genug Beobachtungen angeifellt, um hierin ganz aufs Reine zu kommer. Ich habe mich davon vermittelft einiger am Boden des Glafes angebrachter Zeichen zu überzeugen $\mathrm{Ge}$ legenheit gehabt. Ich that in das Glas eine Wurzel, auf der fich ein Stamm mit zwey Glocken befand, wnd befeftigte fie mit Wachs, fo dafs der Stamm immer an einerley Stelle bleiben muiste. Auf diefe Weife konnte ich leicht vermittelft der gedachten Zeichen während der Bildung des Bäumchens die Stelle beftimmen, wo fich die Glocken im Augenblick ihrer Theilung befanden. Niemals habe ich unter dem Orte, wo die Glocke vor der Theilung feft fafs, den Stiel fich theilen fehen; immer kam aus den getheilten Glocken felbft der ihnen eigene Stiel zum Vorfchein.

Bisweilen habe ich auf den Meerlinfenwurzeln Bäumchen gefunden, deren Aefte fehr dicht beyfamen ftanden und an Glocken ungemein reichhaltig waren. Allein dieje nigen. 


\section{0}

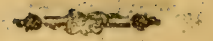

nizen Bäumchen, die ich in den Uhrgläfern felbft entflehen fahe, wollten bey weitem nicht fo gut gedeinen. $\mathrm{Ob}$ ich gleich das Waffer den Tag iiber öfters änderte, und es aus denfelben Gräben fchöpfte, wo ich dergleichen Thierchen in grofser Menge fand, damit fie keine andere als ihre gewöhnliche Nahrurg erhielten, fo konnten fie doch wahrfcheinlich in dem engen Glafe nicht fo reichlich genährt werden, als in dem Graben gefchehen konnte, wo jede noch fo fchwache Bewegung des Waffers immer neue Nahrung herbeyfchaffte. Da fich überdiefs die Nahrung im Glafe auf das einfchränkte, was in einigen wenigen Waffertropfen enthalten war, fo mufste fie nothwendig defto fparfamer werden, je grölser die Anzahl der Th:erchen ward, die dadurch genährt werden follten; daher mufste, wenn fich die Thierchen bis auf einen gewiffen Grad vervielfältigt hatten, dem Fflanzenthiere die zur weitern Entwicklung nothwendige Kraft fehlen. Ift es mit den Bäumchen dahin gekommen, fo wird man in den Glöckchen faft gar keine Körner mehr gewahr; die Zufammenziehungen gefcl hen weit feltener; die Strudel find langfamer und nicht fo fichtbar; kurz alles zeigt, dafs das Planzenthier eingeht, und 
das Bäumchen ftirbt in einem oder zwey Tagen allmählich $a b$.

Nicht alle Bäumchen gehen auf eine und diefelbe Art ein. Bey einigen fondern fich die Glocken auf die obbefchriebene Weife von den Aeften ab, fo dafs der ganze Baum alle feine Glocken verliert, der hierauf viele Tage lang auf der Wurzel nakt ftehen bleibt; ohne weiter zu verderben. Er glei ht dann einem entlaubten Baume. Zuweilen trägt fi hs zu, dafs dieGlocken auf einem Afte ftehen bleiben, indefs die andern Aefte insgefammt alle ihre Glocken verlieren. Wenn ein Aft feine Glocken eher, als die andern, verliert, fo hören in ihm die Zufammenziehungen auf, ja wenn fich alle andere Aefte auf einmal zufammen ziehen, bleibt er gerade und unbeweglich ftehen. Es fcheint alfo, dafs ein Aft abftirbt, wenn ihn feine Glocken verlaffen. Gleichwohl erinnere ich mich, einen Aft bemerkt zu haben, der einige Stunden darauf, als er feine Glocken verlohren hatte, fich auf einmal zu bewegen anfing, indefs der übrige Theil des Baums faft ganz ruhig blieb, fich hierauf um einen andern nahe ftehenden Aft krümmte, und nicht eher ruhete, als bis er fich um denfelben ganz herum gefchlungen hatte. 
Ich habe bereits erinnert, was aus den Glocken wird, wenn fie ton den Aeften los gehen. Wenn SPALLANzani die von den Bäumchen los gegangenen Glocken hat unkommen fehen, fo mufs eine befondere Urfacheihren Tod veranlafst haben. Zuverläfsig kann diefer aufmerkfame Beobachter nicht in einen Irrthum gerathen feyn; in welchen ein anderer wohl fehr leicht gerathen könnte; denn wenn die los gegangenen Glocken eine Zeitlang herum gefchweift find, pflegen fie fich erwähnter Mafsen auf dem Boden des Gefïfses oder fonft wo feft zu fetzen, und dafelbf, zuweilen mehrere Stunden hintex einander, faft ganz unbeweglich zu bleiben; ein Umftand, weshalb man fie wohl für todt zu halten geneigt feyn könnte.

Nichr als einmal habe ich mich auf das gewiffefte zr überzeugen Gelegenheit gehabt, dafs die los gegangemen Glocken, wenigHlens dem gröfsten Theil nach, zu leben fortfahren, ihren Stiel wieder erzeugen, und seue Bäumchen hervorbringen. Uin Weitliuftigkeit zu vermeiden, will ich aus fo vielen Beobachtungen nur eine einzige anführen.

Es hatten fich unter meinen Augen vier Glocken von einem Büumchen abgefondert. 
Während dafs fie in der Flofsigkeit houm fchwammen, nahm ich das Bäumber mit der Meerlinferwurzel, auf welt her dafielbe Itand, heraus. Ich that dafiur eine anilere Wurzel hinein, nachdem ich fie überall mit dem Mikrofkop auf das forgfältigfte unterfucht hatte, um mich zu verfichern, dafs fich auf derfelben kein Glockenthierchen bea fand. Noch vier Stunden fuhren die Glow cken wie vorher zu fchwimmen fort. Einige Stunden darauf fchwammen noch diey ganz ohne Stiel; die vierte hatte fich an die Wurzel mit einem fehr kurzen Stiel angehängt. Den nächfiten Morgen hingen zwey andere an der Meerlinfenwurzel gleichfalls feft, und die vierte hing mit der $W$ and des Glafes zufammen. Alle vier hatten nunmehr etwas längliche Stiele. Ung ef hr fechs Stunden darauf theilten fich drey Glöckchen, jede in zwey; die vierte war noch ungetheilt. Am Abend trug jeder Stiel vier Glocken, and ich bekam in der Folge vier Bäumchen.

-. Zuweilen findet man im Glafe die herr. lichften Bäumchen; die Zufammenziehungen find bey ihnen fehr häufig, die Strudel fchnell; kurz alles ift voll Leben und Munterkeit. Man follte denken, dafs dergleichen Bäumchen viele Tage lang lebhaft und 
an Glocken reichhaltig bleiben würden; und nichts defto weniger verlieren fie ihre Glocken nach einigen Stunden ganz oder doch wenigftens grofsentheils. Im Gegentheil bleiben die Glocken zuweilen auch dann an den Aefichen hängen, wemn man denken follte, dafs fie fich davon trennen müfsten. Ich habe fre von den Aeften vorfätzlich abzufondern gefucht: ich habe dic Neerlinfenwurzeln mit ihren Bäumchen aus einem Glafe ins andere gethan, fie erfchüttert und hin und her bewegt; ich habe die Thierchen hungern laflen, indem ich fie in reinem Waffer auf́bewahrte: das Gedeihen der Bäumchen ift $z$ war dadurch gehindert worden, die Glöckchen haben ein fchlechtes An* fehen bekommen, fie felbft und ihre Aefte haben fich nicht mehr zufanmengezogen, allein alles deffen ungeachtet find fie an ih. ren Aeften hängen geblieben.

Bleiben alfo die Glocken vielleicht eine gewiffe Zeit lang an ihren Aeften hängen, während welcher fie mit denfelhen feft verbunden find, und nach deren Verlauf fie von felbft los gehen, fo wie die Früchte, wenn fie reif find, von ihren Zweigen abfallen? Ich vermuthete dieís Anfangs, fand aber meine Vermuthung nicht befatatigt. Ich hảe 


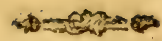

Glorken von ihrer Bäumchen los ģthen fehen, als fich diefe kaum zu bilden angefangen hatten; auch habe ich einige ihren Stiel, der erft vor wenig Stunden gewachen irar, suf der Meerlinfenturzel zur cklaffen, und rai h den gewöhnlichen Umdrehungen in eirer geringen Entfernung ron ihrer exfen stelle bleiben, einen neven Sid hervorreiben, und fich hierauf, wie gewöhnlich, theilen fehen.

Eine andere Art, wie die Bäumchen umkommen, ift folgende. Aus der halbrer faulten Wurzel brechen meiftens fehr feine Fäden hervor, welche, indem fie fich rerlärgern und immer dich*er werden, erftens den Stamm, und hierauf die Aefte und die Glocken derfelben ergreifen. Dex Baum fuhrt, mit diefem Schimmel bef hwert, einige Tage zu leben fort; alleio er kränkelt immer mehr und mehr, bis er zuletzt, ganz damit bedeckt, alle Bewegung verliert, und fo entiftellt ausfieht, dafs man ihn nicht einmal mehr erkennen kann. Ich habe öfters die Wurzel und das Pflänzrhen zu reiniçen ça fucht, wenn fie anfigen mit dergleichen Fädchen bedeckt zu werden. In diefer $\mathrm{Ab}$ ficht hielt ich die Wurzel in dem Glafe, das ich geneigt hatte, mit dem Finger feft, gofs $\mathrm{C}$ a Waffer 
36

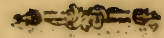

Waffer darauf, und liefs es durch die Wurzel hin fchnell abfliefsen. Vielleicht glückte es mir, den Thierchen ihr Leben dadurch noch einige Tage länger $\mathrm{zu}$ friften; allein endlich wurden fie doch durch die Fäden, die dem kleinen Wafferftrome gröfstentheils, widerftehen konnten, exftickt. Dergleichen Fädchen erzeugen fich auch auf dem Bäumchen felbft. Ja fogar einige von den Pfänzchen, die auf dem Boden des Glafes entftanden waren, kamen auf diefe Weife um.

Diefe Thierchen fterben gleichfalls, wenn man in dem Waffer, worin fie fich finden, Kochfalz, Vitriol, Zucker, Salpeter auflörst; wenn man Saft von Zwiebeln oder Knoblauch hineindrückt; oder wenn man es mit Wein oder Effig vermifcht. Kochfalz, Efsig, reiner Wein töden fie augenblicklich; die andern genannten Dinge find für fie minder heftige Gifte: die Thierchen fahren in der vergifteten Flïsigkeit einige Minuten lang fort, fich zufammen zu ziehen und auszudehnen, indem fre den Mund halb verfchloffen halten, allein endlich fterben. fie doch.

Zuweilen fieht man im Waffer Bäumchen fchwinmen, die von der Meerlinfenwurzel los gegangen find. Da fich derglei-

$$
\therefore \text {. }
$$


chen-Thierchen gewöhnlich auf folchen Wurzeln finden, welche fchon zu verderben angefangen haben, fo kann, wenn das Verderbnifs ein wenig weiter geht, fehr leicht ein Bäumchen los gehen, weil die Theile der Wurzel, womit es verbunden ift, durch die Fäulnifs allen Zufammenhang verloren haben. Ueberdiefs gibt es eine Menge Ungeziefer, das auf den etwas verdorbenen Meerlinfenwurzeln noch Nahrung zu fuchen phegt. Kein Wunder, wenn es dabey die Wurzeln mehr oder weniger mit zerfrifst. Es kann daher das feinige auch mit dazu beytragen, dafs fich die Bäumchen von denWurzeln abfondern. Damit dergleichen Thierchen meinen Pflanzenthieren nicht nachtheilig werden möchten, pflegte ich fie erft $z u$ töden, indem ich das Waffer aus dem Graben kochen liefs, bevor ich es in das Glas, worin die Pflanzenthiere waren, gofs. Die Erfahrung hat mir gezeigt, dafs das Kochen dès Waffers der Nahrung der Bäumchen nicht im mindeften fchadet.

Manchmal bleibt ein halb zerbrochener Aft am Baume hängen; die Glöckchen deffelben leben fort und vervielfältigen fich; der Aft wächft, und wird ein zweiter kleiner Baum, der mit dem erften zurammen-

$$
C_{3} \text { hängt. }
$$


hängt. Es iff ein fchöner Anblick, went man fieht, wie fich dann die Glöckchion beider Bäumchen unter einander verwirren, wie einige auf-und andere niederfteigen, wie fie an cinander forsen, wie fie fich beym Zurammenziehen und Ausdehnen einander durchkreuzen. Ueberdiefs gefchieht diefs nur felten; gewöhnlich geht, ehe fich das neue Bäumchen erzeugt, der andere ein. Main fieht auch zuweilen Aefte, die vom Baume ganz los gegangen find, ocier ganze Gruppen von Glöckchen, oder auch ein einziges Glöckchen mit feinem langen Stiele im Waffer frey hin- und herfchwimmen. Thre Abfondexung vom Baume rührt von einer fremden Urfache her, denn niemals habe ich bemerken können, dafs die Glöckchen im Stande find, ihren Stiel von der Meerlinfenwurzel oder vom Afte, oder den Aft felbft vom Baume los zu machen.

Auch wenn der Baum los gegangen ift, lebt und gedeiheter, wic vorher (und daffelbe gilt von einem Afte, einer Gruppe Giöckchen, ja felbit von einer einzelnen ihren Stiel nach fich ziehenden Glocke). Wenn in diefem Falle eine Zufammenziehung erfolgt, und fich alle oder die meiften Atite zufammenziehen, fo nähern fich nun- 
mehr nicht die Aefte und die Glocken dem Stamme, fondern der Stamm und die Aefte den Glocken; eine Erfcheinung, die auch Herr SPALLANZANI beobachtet hat.

Vielen dergleichen Aeften und Guppen, fo wie einzolnen ihren Stiel nach fith zichenden Glacken, habe ich Meerlinfenwurzeln in das Gias gevorfen; allein niemals habe ich bemerken äonnen, daís ein Aft, eine Gruppe Glöckchen oder eine einzelne Glocke fich daran fett gehängt hätte. Es ftheint folglich, als cb die einzige Art, wie frch die Glöckchen an den Körpern befeftigen, darin befteht, dafs fie befchriebener Mafsen ihren Hintertheil an diefelben halten, indefs fie ihren Stiel zu entwickelu anfangen.

Die gewöhnliche Höhe der Bäumchen, von denen ich jetzt recie, beträgt ein wenig uber eine Linie. Die Münduug der Glocken beträgt im Durchmeffer ungefähir $\frac{x}{3} \frac{\mathrm{Li}}{\mathrm{a}}$ nie, und die Länge derfelben übertrifft den Durchmeffer etwa um ein Drittel. Nach Jem hintern Ende zu wird die Glocke mmer enger, und da, wo fie mit dem Stiele zufammen hängt, if fie am engften. Die Lïnge der Stiele ift fehr veränderlich; fo wie aurh die Länge der Aefte. Der Stamm ift

$$
\mathrm{C} 4 \text { : ge- }
$$


gewöhnlich $\frac{x}{3}$ Linie oder ein wenig darüber lang *).

Wenn ich ein Bäumchen meffen will, fo fchneide ich das Stückchen der Meerlinfenwurzel, worauf es fich findet, ab, bringe daffelbe fammt den Bäumchen auf ein dünnes Blättchen von rulfichem Glimmer, und laffe darauf vermittelft einer Schreibefeder einen ganz kleinen Waffertropfen fallen. Hierauf lege ich den Glimmer auf den Träger (porta - og : getii), fo dafs das Waffer unten hin kommt, und bringe das Mikrometer gehörig an. Ich brauche ein Mikrometer vom P. Іон, BAPTISTA von S. Martino, deffen grofse Einsichten, fo wie feine Verdienfte um die Vervollkommnung phyfifcher. Inftrumente, hinlänglich bekannt find. Man mufs fich einer fehr wenig fcharfen Linfe bedienen, um

- Man fieht recht gut das ganze Bäumchen mit der Linfe 90 . Um die einzelnen Theile deffele ben deutlich wahr zu nehmen, muls man fchärfere Linfen bis 400 brauchen. Braucht man die Linfe too, fo mufs man das Objekt abwärts kehren, um das Glas nicht zu befchmu? tzen.

Unter der Linfe 96 verftebe ich diejenig; - clche den Durchmeffer des Objekts ungefzinr g, 0 Mahl vergrofsert, $u_{0} T_{0} w_{0}$ 
in den Brennpunkt, fo viel als möglich, zu gleicher: Zeit die Felder des Mikrome. ters und, das Bäumchen zu bekommen.

\section{2.}

Es gibt eine andere Art von baumför migen Thierchen *), welche einem eigentlichen Baume noch ähnlicher ift, als die bisher befchriebenen. Ihre Hauptäfte entfpringen nicht faft alle aus einer und derfelben Stelle des Stammes, wie bey jenen der Fall ift. Der Stamm, die Aefte, die Stiele zeigen hier nicht die Art von Zufammenflechtung, von welcherich fchon gefprochen habe. Die Bäumchen der erften Art fehen unter dem Mikrofkope, mit gebrochenen Lichtttrahlen betrachtet, gleichfam perlfarbig aus, da hingegen die zweyte "Art geibliche Glocken hat.

Die Höhe des ganzen Baums ift meiftens $\frac{3}{4}$ Linie. Die Glöckchen find nichtlänger, als $\frac{x}{48}$ Liniẹ, und verhältnîsmäfsig noch enger, als die Glacken der erften Art ; denn der Durchmeffer der Mündung beträgt höch: ftens etwas über, die Hälfte von der Achfe.

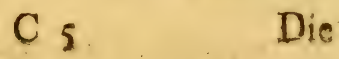

\%) Fig, II. 


\section{$\Rightarrow=x$}

- Die Glöckchen ziehen fich nach dem hintern Theile nicht zufammen, wie die oben befchriebenen Glocken, und die Mündung ift wenig oder gar nicht weiter, als der übrige Theil des Körpers. Mit Einem Worte, diefệüumchen unterfcheiden fich von den vorhergehenden an GröIse, Farbe und Struktur; fie haben einen andern Stamm, andere Aefte, andere Stiele, andere Glöckchen. Inzwifchen kommen beyde Arten in fehr vielen Dingen auch mit einander überein. Auch hier rollen fich Aefte und Stiele und Glocken zufammen, und nülien fich der Meerlinfenwurzel, entrveder von freyen Stücken, oder bey der geringften Erfchütterung des Glafes; nur entwickeln fie fich hierauf weit langfamer wieder, als die Aefte und Stiele der Bäumchen der erften Art. Auch hier fnnd die Ränder der Glöckchen mit Spitzchen befetzt, die nicht immer fichtbar find. Endlich gibt es auch his den obgedachten Strudel um die Oeffnung der Glöckchen. Diewenigen Beobachtungen, weiche ich bis jezt über diefe zwveyte Art von Bäumchen angefiellt habe, haben mir von ihrer Natur und. Oekonomie nichts weiter gezeigt.

Erlauben Sie mir, einige Gedanken bey zufigen. Gibt es in der Natur ein Gefchöpf, 
fchöpf, das; weil es thieris he und veretabilifchie Eigenfchiaften zu gleicher Zuti befitzt, gleichfam den Uebergang vom pianzerreich zum Thierreich macht? Angenommen, dafs es dergleichen Gefchöpfe gibt, follte man denken, dafs es Wefen feyn müfsten, welchie, indefs fie thierifche Funktionen verrichten, fich unter der Geltalt eines Baumes zeig n, ihre Aefle, wie ein Baum, ausdehnen, vergröfsern und vervielfiltigen, and, wit ein Baum, an einer Stelie beteftigr find. Reichen aber auch diefe äusern Kennzeitien, die fie mit den Bäumengemein haben, wirklich hin, um denfelben vegerabilitche Eigenfchafien mit Recht zufchreiben $7 . u$ können? Müfsten fie fich dann den Pfianzen nicht auch in Rückficht der Organifation bis auf einen gewiften Grad nähtern, um auch vegetabilifche Funktionen verrichren zukönnen? Herr Daubenton ift der Meinung *), rafs man, un zu entdecken, ob es zwifchen den Pflanzen und Thieren Zwifchengefchöpfe gibt, welche vernöge gewifler dem Thier und Pfianzenreiche gemeinlchaftlicher Kennzeichen, die fle befitzen, einen alls

a) Introd. à l' hitnire natur. Enç̧clog. méchod. Diotion. vidarap. 
allmällichen Uebergang von dem einen $\mathrm{Na}$ turreiche ins andere machen, diejenigen Pflanzen, welche die gröiste Menge Organe haben, mit denen Thieren, welche davon am wenigften befitzen, vergleichen müfie. Er gründet feine Mleinung darauf, dals, weil der Mechanismus des thierifchen Körpers, überhaupt betrachtet, zufammengefetzter, als des vegetabilifchen, ift, die Thiere auch an Organen reicher feyn müffen. In der That braucht die Pflanze keine andern Organe, als die zur Ernihrung und Entrvicklung nöthig find; da hingegen im Thiere die animalifchen Funktionen noch andere Organe erfordern, fo dafs es freylich fcheint, man könne daraus fchliefsen, dafs die Wefen des Thierreichs eine grölsere Anzakil Organe, als die Pflanzen, befitzen muifen. Wenn man indeffen bedenkt, dafs die Natur in beyden Reichen ihre wunderbaren Wirkungen auf unendlich mannigfaltige Arten zu verändern pflegt; dafs fie in vielen Fälen ihre unerfchöpfichen Reichthümer gleichfam verfchwendet, indem fie Mittel, ihre Endzwecke zu erreichen, wie es uns vorkommt, auf eine ungeheure Axt vervielfiltigt; dafs fie hingegen in andern Fällen ihre Abfichten duxch fehr einfache Mittel zu exreichen weifs: fo kann man

leicht 
leicht auf den Gedanken kommen; dafs in denjenigen Pflanzen, welche die Natur mit Organen gleichfam verichwenderifch âusgeftattet hat, die Organifation zufammengefezter ift, als in denen Thieren, wo fie damit fehr fparfam gewefen ift. In der That hat es ganz das Anfehen, dass ein Armpolyp, der wirklich weiter nichts als eine Art von Darm ift (wie auch Herr BonNET erinnert), und ein Infufionsthierchen, das nur aus fehr wenigen Bläschen befteht, einfachere Gefchöpfe find, als ein Baum, der fo viel und fo verfchiedentlich organifirte Theile enthält. Gibt es aber eine einzige Thiergattung, die weniger Organe befitzr, als eine einzige Pflanzengattung, fo ift es falfch, dafs die Natur in der Erzeugung ilirer Gefchöpfe vom Pflanzenreiche zum Thierreiche vermittelft einer zufammengefetztern Organifation auffeigt, und die ron dem berühmten DAUBENTON vorgefchlagene Methode, die Mittelglieder zwifchen dem Pflanzen- und Thierreiche zu entdecken, kann fchlechterdings nicht Statt finden.

Ich glaube daher, dafs man, wenn man unterfuchen will, ob es in der Natur Weferi gibt, welche den Uebergang vom einen diefer zwey Naturreiche zum andern maxhen, einen 


\section{5}

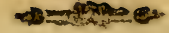

cinen andern Weg einfch]agen muss. Ohne Zweifel werden die Funktionen der organifirten Wefen von verichiedener Natur feyn, nachdem die Verrichtungen der Organe verfchieden find. Daher kommt es, dafs die thierifchen $F$ unktionen Organe erfordern, dew ren Struktur ganz anders ift, als die Struktur der Organe, welche den vegetabilifchen Funktionen eigen find. Folglich wird eher die Einrichtung der Organe, als die Anzahl derfelben, den Cliarakter eines vegetabilif hen oder animalifchen Wefens abgeben können. Sucht man daher den Uebergang von dem einen der gedachten zwey Naturreiche in das andere, fo mufs man meines Erachtens nicht for ohl auf die Menge, als auf die Einrichtung undBefchaffenheit der Organe fehen. Fincie ich alfo ein Thier, in deffen Organifation frich zugleich dasjenige zeigt, was die Organifation der Phanzen wefendit hes hat, fo wercle ich daffelbe, ohne auf die Anzahl feiner Organe im mindeften zu arhtev, für ein Tiefen halten, das zugleich dem Fflanzen- und dem Thierreiche angchört.

- So verfchieden auch die Wefen des weitlüuftigen Thierreichs crganifint find, fo kcmmen doch alle darin iberein, dais fie vie Speife durch ein einziges Organ einzichery, 
worauf fie in eine oder mehrere Höhlungen gefchafft wird, wo fie die erften Veränderun gen erleidet *). Im Gegentheil ziehen alle Gewächie, zu welcher Klafie fie auch immer gehören mögen, den $\mathrm{Nak}$ angssfaft durch eine Menge Saugwerkzeuge ein, worauf er lüngs den Fibern der Pflanze aufizteigt. Alro find ein Mund und ein Magen Organe, die cem Thiere eigenthümlich zukommen; hingegen eine Menge Wurzeln cder andere Saugwerkzeug, welche die Stelle derfelben vertreten, find eigenthümliche Organe der Pflanze. Nun wollen wir fehen, wie fich die Organifation der baumförmigen Thierchen zu der Organifation der Pflanzen verhält, um daraus den Schlufs zu ziehen, ob diele Gefchöpre einiger Mafsen auch zum Planzenreiche gehören, oder nicht.

*) Der Banáwurm zieht feine Nahrung vermittelt der vier Warzen ein, die fich am Kopfe delfelo ben befinden. Allein diefe Warzen kommuniciren mit einem und demfelben Crgan, in das die von ihnen eingefaugte Spcife alsdann übergeht. Man nufs fie daher nicht als vier Mén ler des Thieres, fondern als vier Verlänges:ungen des fonderbar gebildeten Mundes deffelben betrachten. Die Wurzeln der Pflanzen find 55. was ganz anders, 
Ich haue 'einen Baum um, indem ich Zweige! und Blätter darauf laffe. Obgleich die Pflanzen atich durch die Blätter einige Nahrung überkommen, fo thört doch der Baum auf, zu vegetiren, und firbt ab. Im Gegentheil nehme ich ihm alles Laub: noch mehr, ich fchneide alle Aefte $a b$, und lafie Dlos den nackten Stamm ftehen; und er fährt zu leben fort, treibt neue Zweige, und bekleidet fich mit frifchem Laube. Woher fommt diefs? - Man mufs mit Herrn BONNET die Haupt - und Nebenäfte der Bäume für eben fo viel einzelne Pflänzchen anfehen, die auf einander, und alle auf die ge. meinfchafiliche Pflanze gepfropft find. Der von den Wurzeln angezogene Nahrungsfaft fteigt in Stamme auf, und geht gleichfam aus der Mutterpflanze in die eingepfropfter Pflänzchen über, die mit derfelben ein Ganzes ausmachen. Wenn ich alfo den Baum von den Wurzeln abhaue, fo entziehe ich ihm die Organe, welche die Nahrungsfäfte deffelben aus der Exde anzuziehen beftimmt.find, folglich die zu feiner Erhaltung nöthige $\mathbb{N}$ ahrung; allein wenn ich nur die gleichfam eingepfropften Pflänzchen von ihm wegnelhme, fo fährt die Mutterpflanze fort, fich immer noch mit den Säften zu nähren, welche fie, wie zuvor, durch die Wuzzeln erhält und welche, 
weiche, indem fic fich zwichen cen Fiberm derfelten bevregen, einen Theil de darin, enthalteren Keime von neliem entwickeln.

Ich fchncide gleichfalls ron der Mecr. linferwurel den Stanm eines unfere: Ther chen ab, oder ich reifse cinen Aft rom. Siamme deffelben los. Ins enften Falle firbt das Bäumchen eben fo wenig, als der Aft im. zweyten; vicimde finden in beyden Fällen, wie vorher, die Theiluner der Giuken und die Vervielabigung und Verlängerung der Aefte Statt. Lafie ich hirgegen den Stamm ohne Zweige, oder einen Aft ohne Glocken, fo pllegen fie kein Zeichen ton Leben weitex von fich zu geben.

Ich habe es fchon Anfangs gefagt: unfer Pflanienthier ift eigentlich nichts als eine Gruppe von Thierchen, die unter fich rer mittelft ihrer Stiele kommuniciren, deren Vereinigung die Neben - und Hauptäfte und den gemeinf haftlichen Stamm ausmacht. Iedes Thierchen erhält feine befondere Nahrung duxch das einzige Organ, das der animalif hen Natur des Thierchens zuFoige hierzu beftimmt ift, und fetzt fiefodarm in die Säckchen oder Bläschen ab, welche die Stelle ies Magens ver * treten; dafelbft erleidet die Speife vermöge der Wirkıng dexfelben die nöthigen Verän 
derungen, wird gehörig ausgearbeitet, und nährt fodann den Körper und den Stiel des Thierchens. Da aber aus der Vereinigung der Stiele die Aefte, fo wie aus der Vereinigung der Aefte der Stamm, entfpringen, fo geht die Nahrung von dem jedem Thierchen eigenthümlichen Theile, dem Stiele, in den vielen Thierchen gemeinfchaftlichen Theil, den Aft, und zuletzt von denAeften in den allen gemeinfchaftlichen Theil, den Stamm, über. Da man nun bey unfern Thierchen in Rückficht der Ernährung eine Oekonomie gewahr wird, die von derjenigen, welche bey den eigenflichen Bäumen Statt findet, ganz abweicht, die dexjenigen ganz unähnlich ift, vermöge welcher die Pfanzen fich ernähren, fo follte man wohl berechtigt feyn, daraus den Schlufs zu ziehen, dafs auch ihie Organifation von der Organifation dex Pflanzen ganz verfchieden ift, und dafs fie folglich zum Pflanzenreiche durchaus nicht gerechnet werden können.

Bey dem allen könnte doch wohl diefer Schlufs noch ein wenig voreilig feyn. Wer verfichert mir, dass, während diefe Pflanzenthiere fich nach Art anderer Thiere nähren, fie nicht auch nach Art der Pflanzen einige Nahrung einziehen? Wäre es nicht 


\section{$S 5$}

möglich, dafs', wïhrend die Glöckchen durch die Speife, weiche fie einziehen, fich und die gemeinfchaftliche Pflanze ernähren, diefe auch vom Boden, wo fie feft fteht, etwas Nahrung überkommt? Man wird mir einwenden, wenn die Pflanze, nachdem die Aefte ihrer Glöckchen beraubt worden, gleichfam nicht weiter vegetire, fo fey diefs ja nffenbar ein Zeichen, dafs ihr die Nahrung felile, und dafs fie folglich von der Metrlinfenwurzel keine erhalte. Allein diefs kann höchftens beweifen, dafs die Nahrung, welche fie von der Wurzel ïberkommt, (im Fall fie wirklich fo genährt wird) nicht hinreicht, fie munter und lebhaft zu erhalten, aber nicht, dafs die Wurzel zu ihrer Ernährung ganz und gar nichts beyträgt. Ueberdiefs ift es ja unmöglich, dafs in ihr, wenn fie ihre Glöckchen verloren hat, weiter eine Entwickelung vor fich geht, da blos in den Glöckchen, aber nicht in dem Stamme oder den Aeften, die Keime verborgen liegen, wie aus der Art der Bildung des Bäumchens deutlich erhellt.

Um, wo möglich, diefen Zweifel zuheben, habe ich nicht unterlaffen, einige Verfuche anzuftellen.

Ich habe zu einer und derfelber Zeit in

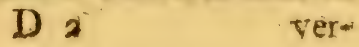




\section{$\rightarrow=90$}

verfchiedene Uhrglïfer verfchiedene Bäumchen gethan, einige mit der ganzen Meerlinfenwurzel, andere blos mit dem Stückchen der Wurzel, auf welchem fie feft ftanden, und noch andere ohne die Meerlinfenwurzel, von welcher ich fie am Einde ihres Stammes abgefchnitten hatte. Ich dachte, wenn die Meerlinfenwurzel dem Pfänzchen wirklich etwas Nahrung gäbe, fo müfsten die Bäumchen, deren Wurzel noch ganz war, mehr, als die andern, gedeihen; diejenigen, die fich blos auf einem Sückchen der Wurzel befanden, müfsten nicht fo gut, als die erften, fortkommen, weil fie aus ider Wurzel weniger Nahrung anzuziehen im Stande wären; endlich diejenigen, welche von der Wurzel ganz abgefondert waren, mülsten in Rückficht des Gedeihens allen andern nachiftehen. Ich habe diefen Verfuch mehr als einmal wiederholt. Allein die Refultate, die ich erhielt, waren fo verfchieden und einanderwiderfprechend, dafs ich daraus nichts fchlieffen konnte. Auch war es eben nicht fehr fchwer, diefs roraus zu felien. Dergröfsere oder gerinǵgere Ueberinfs an Nahrung in den verfchiedenen Uhrgläfern, die gröfsere oder geringere Anzahl der Thierchen, die davon leben wollten, das verfchiedene Alter der Büumchen, die gröfsere oder geringere Leb- 
haftigkeit der Pflanze, je nachdem ihre individuelle Konftitution befchafien war, alle diefe Umfiände mufsten nothwendig die Refultate der Verfuche fo verfchieden und mannichfaltig, als ich fie wirklich beobachtet habe, machen.

Von der Unzweckmälsigkeit diefes erften Verfuchs überzeugt, ging ich zu einem andern über.

Ich hatte gefehen, dais viele Giöckchen, die von den Jäumchen los gegangen waren, nachdem fie fich lange Zeit herungetrieben hatten, zuweilen am Boden des Glafes ftehen blieben, und dafelbft ein nenes Bäumchen hervorbrachten. Diefs veranlafste mich, Aclit zil geben, wie die am Glaie feft ftehenden Bäumchen, mit den an den Neerlinfenwurzeln feft hüngenden verglichen, wohl forthommen möchten. Ich fuchte mir daher B̈̈umchen zu verfchafren, welche auf den Wïnden des Glafes feft ftanden. In diefer Abficht wayf ich, wenn eine Glockeron einềm Bäumchen los geganģen war, die Meerlinfenvurzel, auf welcher fich das Büumchen befand, weg, und liês das Glöckichen alleir im Glafe, das, wenn es einige Zeit lang im Wafler herum gefchwommen war, an der 
Wand des Glafes hängen blieb. Zu gleicher Zeit hielt ich in befondern Gläfern Bäumchen auf Meerlinfen:vurzeln. So konnte ich auf einmal Bäumchen aufMeerlinfenwurzeln und an den Wänden des. Glafes beobachten. Allen diefen Gefchöpfen gab ich einerley Waffer; bey allen verwechfelte ich zu einer und derfelben Zeit das alte Waffer mit frifchem; allen gab ich, fo viel als möglich, gleich viel Waffer; kurz, ich fuchte die Umftände auf beyden Theilen vollkommen gleich zu machen. Das Refultatwar folgendes. Unter einer grofsen Menge von Bäumchen, die fich an den Wänden der Gläfer erzeugt hatten, hat auch nicht ein einziges fo fortkommeri wollen, wie die meiften von denen fortkamen, welche auf Meerlinfenwurzelnftanden, und von mir zu gleicher Zeit ernährt wurden.

Diefs fcheint $z u$ beweifen, dafs das Pfänz: hen auch aus der Wurzel Nahrung an fich zieht. Indeffen geitehe ich, dafs ich davon bey weirem norh nicht überzeugt bin. Ich habe noch nicht genug Thatfachen fammeln können, die alle daffelbe darzuthun im Stande wären. Irh habe die Verfuche noch wi h penug abgeändert, um entdecken zu könneli, ob das Phänomen wirklich von 
der Urfache, von welcher es herzurihihen fcheint, oder von einer andern bis jetzt verborgenen abhängt, die eben durch die Vervielfältigung der Verfuche vielleicht entceckt werden könnte. Wäre es zum Beyfpiel nicht möglich, dafs die Körperchen, womit fich die Thierchen nähren, ihrer gröfsern Schwere zu Folge im Waffer allmählich zu Boden finken? Was würde aber hieraus folgen? Die Bäumchen auf den Meerlinfenwurzeln haben im Glafe meiftentheils eine horizontale Richtung. In diefer Lage müften viele ihrer Aefte, befonders wenn fie fich verlängert haben, den Boden des Glafes berühren. Wenn nun die Glöckchen diefer Aefte dafelbft Strudel erregen, fo müfsten fie natürlich fehr viel Nahrung einziehen können. Noch mehr: indem fie fich zufammenziehen, und dem Stamme nähern, kehren fie gleichfam den Boden des Glafes aus, wodurch die Körperchen wieder in Bewegung gerathen, und in die Höhe getrieben iverden wiirden, wo die andern Glöckchen liegen, die auf diefe Weife gleichfalls reich'ich genährt werden mürsten. Die auf dem 3oden des Glales feft ftehenden Bäumchen lingegen würden, da fie fich in einer fenkrchten Richtung befinden, folglich ihre A.tte in den höhern Wafferfchichten haber, 
56

an Nahrung grofsen Mangel leiden. Und da fie, indem fie ficti zufamménziehen, cien Boden des Glafes zu kehren nicht im Stande find, fo wirden fie nicht einmal die Ǩ̈öperchein vom Boden in die höhern Waiferfchichten, wwo fie ihre Glöckchen haben, trciben können. - Vielleicht fetzt auch die Necrlinfenwurzel, indem fie in Faulnifs übergeht, in das Waffer eine grofse Menge yon Körperchen $a b$, weiche clie Thierchen zu nähren gefchickt find. In dieferm Falle wurden die Bäumchen in den Gläfern, wo Meerlinfenwurzeln find, rcichlichere Nahxung finden, als in deneen, wo dergleichen Wurzeln fehlen; folglich würden die Baumchen, die ich aif Meerlinfenwurzeln zog, weit beffer, als die am blofsen Glafe hängenden, haben gedeihen kömnen, wenn auch keine Nahrung aus der Wurzel in das Plänzchen durch den Stamm aufgeftiegen wäre.

Ich geftehe es, als ich jene Verfuche anfiellte, habe ich mein Augenmerk auf diefe zwey Umftände nicht gerichtet. Wenn ich fit wiedertolen werde, will ich die Meer. linfen "urzeln mit Wa! hs ankleben, fo da die darauf ftehenden Bumchen ihre Aefte it die Höhie halten müffen. Eben fo gedenle 


\section{7}

ich alsdann der Fäulnifs nahe Meerlinfen. wurzeln auch in die Gläfer zu thun, wo Büumchen an den blorsen Wänden derfelben feft hängen. Aưf diefe Weife ird fich entfcheiden iaffen, ob die gedachten zwey Cmftände auf das Gedeihen der Bäunchen einen Einflufs äuisern können.

\section{3.}

Oftmals fand ich, wenn ich meine gewöhnlichen Bäumchen fuchte, auí denfeliben. Meerinfenwurzeln eine Art ron Straufspolypen *), die gleichalls zu der Klafe der laumfömigen Thierchen gerechnet werden können, weil auch fie einen Stamm befitzen, aus welchern mehrere Aefle entfpringen, die fich in kleinere Aefte theilen ws). Ich will fie hier kixzlich um fo lieber befureiben, da fie mir von Trembers's Straufspolypen, ron welchen Spaldanzanr fprichit, wo er zwifchen denfelben und feinen baunformigen Thierchen eine Vergleichung anftellt, etwas verfchieden zix feyn fcheinen. Ich folgere diefs aus drey Verichiedenheiten, die ich zwifchen SPALLANzAni's Straufspoly-

$$
\text { D } 5
$$

pen

*) Polipi a mazzetto, a fiocco. Albercti a f́occo. Wis. Fir. III. 
pen und den von mir beobachteten bemerke. Erftens befitzen jene an ihren Glocken keine Spitzchen; die Glöckchen der meinigen hingegen find damit verfehen. Zweytens können fich die Glocken jener nicht fo zufammenzichen und ausdehnen, wie die Glocken der meinigen. Endlich werden die Aefte jener zwar nicht willkührlich, aber doch wenn das Waffer bewegt wird, eingezogen und ausgedehnt; die Aefte diefer hingegen bleiben immer ganz unbeweglich.

Aus dem Stamme diefer dritten Art von baumförmigen Thierchen entfpringen an einer und derfelben Stelle einige Aefte, die unter einander faft gar nicht divergiren. Etwas weiter oben theilen fich diefe Aefte in andere kleinere Aefte, die unter einander gleichfalls fehr wennig divergiren, Alle Hauptäfte, fo wie auch alle kleinere Nebenzweige, find fatt von gleicher Länge, und unter einander ähnlich. Daher kommt es, dafs die Glöckchen, die fich blos am Ende der Aefte befinden, alle rom Stamme faft gleich weit abftehen, und wegen der geringen Divergenz der Aefte fehr natie an einander find. Mitten aus diefem Haufen von Glöckchen, in welchen fich der Straufs zu endigen pflegt, erhebt fich zuweilen, wiewohl fehr felten, 
eine zweyte Reihe von Stielen, die fich in eine zweyte Reihe von Clöckchen endigen, fo dafs ijber dem einen Strausse ein anderes kleines Sträulschen fteht.

Stamm, Aefte und Stiele find weifs, nicht gewunden, wie bey den Büumchen der erften Art, und, wie fchon erinnert worden, olne alle Bewegung, Der hintere Theil der Glocken ift gleichfalls weifs; der vordere, der Länge nach zwey Drittel jeder Glocke, mit gebrochenen Lichtitrahlen betrachtet, gelblich. Die Glocken können fich zufammen ziehen, und hierauf wieder ausdehnen. Indem fie fich zufammen ziehen, verfchliefsen fie die Mïndung völlig. verkürzen fich faft um die Hilfte, und. werden zugleich etwas dicker *). Sie verkürzen fich in einem Augenblick, verlïngern. fich aber erft nach und nach wieder. Zuweilen verkürzen fie fich von nesiem, ehe fie fich völlig wieder ausgedehnt haben, und wiederholen dafielhe Spiel mehrere Fiall hin ter cinander. Diefe Verkürzung erfolgt von freyen Stiicken, gefhietit aber auch dann, wenn man das Wafter ein wenig be-

wegts 
wegt. Sie öfinen thre Mündung wieder, wenn fe fich faft ganz wieder auscedehnt haben, und in demfelben Augenólicke werden ihre Spitzchen fichtbar, die fich bey einigen Glocken auch dann zeigen, wenn die Mindung offen ift. Alsdann bewegt fie clas Thier entweder, oder zieht fie zurïck, oder hilt fie unbeweglich and meiftentheils unter einander konvergirend. $\mathrm{E}_{6}$ hat mir gefchienen, dafs fre von der innern Seite der Münrung herauskommen. - Das Ende der Mündung if mit cinem etwas dicken Rande eingerafst.

Wenn die Thierchen fich theilen wollen, fo rerlafien fie die glockenoumige Gefialt, werden rundlich, und eregen keine Wirbel mehi. Thre Theilung gefchichtzwar der Länge nach, aber doch nicht fo, dafs die Theile vollkommen gleichwerden. Auch verlieren fie àie Glockenform, und nehmen die Geftalt einer Zwiebel an, ehe fie fich von iliren Stielen abforidern. Da hier ganz diefelben Erfcheinungen Statt finden, welche man bey den Giöckclien der baumförmigen Thitrchen der erften Art bemerkt, fo verweife ich auf dasjenige, was ich bereits crinnert habe, als ich von der Art und Weife 
Weife fprach, wie fich jene Bäumchen fortpllanzen. *)

Die gewöhnliche Höhe der Straufspolye pen betrïgt ungefi hr eine Linie. Ihre Glückchen kommen der Lïngenach mit den Glöck chen der Biumchen der exflen Art ziemlich überein; allein ihre Breite ift um rieles kleiner.

\section{4.}

Eine andere Art von Straufspolynen pflegt fich an vcrfchiedenen Gatturgen vou Thierchen, die fich in den Gräben finder, aufzuhalten. Ich habe dergleichen oben auf dem Kopfe, auf den äfligen Amen einiger diefer Thierghattungen, auf dem Rücken, um die Beine, auf der Schaale sewilfer fehr kleiner Schnecken des füfsen Wafers gefinden. Inmer hingen fie mit Thieren zufammen.

Thre Glöckchen find perlfarbig, und ant Randegleichfalls mit Spitzchen verfehen. Sie eiregen Wirbel. Sie zichen fich, wie die Glöckchen der vorhergeheriden Axt, zufam-

men;

4) Auch diefe Gefchöpfe werden mir denfelben Linfen betrachtet, deren ich folion oben ge daclut habe. 


\section{2}

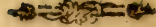

men, und raben eben fo, wie jene, unbiegfame Stiele. Diefe Stiele find fehr kurz, und da, wo fie mit dem 'Thiere zufammen hängen, unter einander verbunden.

Diefe Gefchöpfe find weit kleiner, als die vorigen. Sie müffen nicht mit einer andern Art von Glöckchen verwechfelt werden, deren weiter unten ${ }^{*}$ ) gedacht.werden wird.

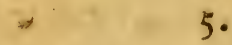

Noch glaube ich hier eines andern Ged fchöpfes viurzlich erwähnen zu müffen, das mir gleichfalls eine Polypenart zu feyn f(heint **). Ob dem wirklich fo ift, wage ich nicht $7 . u$ beftimmen, denn ich habe noch nicht auf eine ïberzeugende Weife entdecken können, ob diefe Gefchöpfe zum Thierreiche wirklich gezählt werden müffen. Sind es Thiere, fo gibt es gewifs auf der Welt keine unempfindlichere Thierart. Man bemerkt bey ihnen keine Zufammenziehung und Ausdehnung; die Stiele und die Glocken find unbeweglich; man fieht keine Spirzchen, keine Bewegung der Lippen, keine Wirbel. 


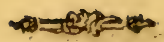

Als ich einft einige, die los gegangen waren, beobachtete, bemerkte ich bey itnen Bewegungen, die mir willkührlich zu feyn fchienen. Sie dreheten fich herum, begaben fich vorwärts, kehrten dann wieder zurück, allein immer auf eine fehr träge Art, während dafs das Wafter und die darin enthaltenen Körperchen volikommen ruhig waren. Diefe Bewegungen fcheinen hinreichend zu feyn, uns von der thierifchen $\mathrm{Na}$ tur diefer Gefchöpfe zu überzeugen; und dennoch zweifle ich noch daran. Vielleicht hatten einige ganz kleine Infufionsthierchen, die darauf lagen, jene Bewegungen verurfacht. Wie oft bemerkt man nicht bey der Unterfuchung eines Aufgufies Körperchien, denen man eine willkührliche Bewegung shne Bedenken zufchreiben würde, wenn nicht alle Bewegung fogleich aufhörte, fo bald das Thierchen, von dem fie eigentlich herrührt, und das darauf liegt, davon getrennt worden ift, worauf man denn deutlich fieht, dafs fie eigentlich weiter nichts als Stückchen einer verdorbenen Materie find.

Die Glocke diefes Gefchöpfs hat die Geflalt eines länglichen Kegels, uni ift röthlichgelb. Dex Stiel ift gewöhnlich noch einmal fo lang, als die Glocke, zuwei- 
64

len abcr avch vicl länger. Oft frebt mai nur eiren oder zwey Kegel auf Einen Stiele; zuweilen bemerkt man aber auch cine Art von Strauchwert, das aus einem Stam: me und aus zwey oder drey Aefichen, roronjedes fich in einen kleiren Kegel cndigt, befteht.

Sind diefe Gefchöpfe wirklich Thiere, fo fnd fie die kleiviten unter allen von mir beobachteten Glockenthierchen ").

\section{6.}

Ich wende mich nun zu einizen andern Glockenarten, die fich von deren, waus die Bäumchen beftehen, unterfcheiden, ob fre ihnen gleich in Rückficht der Struktus älinlich find. Ich geftehe Thnen aufriblitieg Aniangs habe ich fre mit den Glöckchen der baumformigen Thierchen, eben viegen der fehr grofsen Aehnlichkeit, welche zwifhen beyden Gatungen Statt findet, verwerhelt. Alich Herr SPALLANZAN hat dergleichen Glocken beobarhtet; dern die Clörkcher, welrle er das erfte Miahl auf den Wurzeln. feiner Mieerlinfe fand, gehören zu einer der.

$$
\mathrm{Ar}-
$$

.5*) Ich habe fie mit tinfen ron 150 bis 700 bee obacksces. 
Arten diefer Gefchöpfe, die ich fogleich befclireiben werde. Ich zweifle gar nicht, dafs diefer grofse Naturforicher von diefen Gefchöpfen die Glocken der Büumchen, welche er fechs Tage fpäter dafeibst fand, augentlicklich unterf tieden haten wird, ob er gleich dem Lefer davon nichts meldet.

Die Meerlinfenwurzeln pllegen an diefen Glöckchen weit reichhaltiger zu feyn, als an den Giocken der Bäumchen. Un fie zu finden, darf man nur mit einer Lupe nachaforkchen, ob es an den Meerlinfenwurzeln geviffe weifse Punkte gibt, diefich, wenn man das Waffer cin wenig erichüittert, einander, fo wie der Wurzel, năhern, und hierauf, wenn das Waffer ruhig wird, wieder entfernen und etwas zerftreuen. Auch fie pflegen diejenigen Wurzeln, welche ein wenig zu verderben anfangen, vorzuziehen; indeffen trifft man auch welche auf ganz gefunden Wurzeln an. Gewöhnlich findet man fie gruppenweife, obgleich der Stiel einer jeden Glocke auf der Meerlinfenwurzel einzeln und von den Stielen dex andern Glo• sken abgefondert fteht.

So wie ich bemerkt hatte, dafs die Gloo cken der. Bäumchen, wenn fie irgendwo feft hingen, immer neue Bäumchen exzerg. 
66

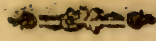

ten, die an den Meerlinfenwurzeln unmittelbar hängenden Glocken hingegen niemals ein Bäumchen hervorzubringen im Stande waren, fahe ich ein, dafs die Vertheilung der Glöckchen entweder einzeln um die Meerlinfenwurzeln herum, oder in die Form von Bäumchen keinesweges etwas zufälliges feyn konnte. Als ich nun, um den Grund diefer Verfchiedenheit zu entdecken, ihxen Theilungen nachfpürte, ward ich bald gewahr, dafs bey den Glocken mit abgefonderten Stielen, wenn die Jungen fich völlig entwickelt haben, zwifchen denfelben und der Mutterglocke weiter kein Zufammentang Statt findet, da hingergen bey den Bäumchen die Jungen mit den Alten auf dem gemeinfchaftlichen Afle bleiben. So wie ein Junges die Glockengeftalt angenommen hat, verliert es diefelbe früher oder fpäter wieder, fteckt hinten die Fädchen aus, bewegt fie eine gute Weile auf die oben befchriebene Art, läfst reinen Gefellfchafter auf dem alten Stiele fte. hen, fetzt fich anderswohin, und bringt ein neues Gefchöpf hervor. Diefs ift die Urfache, warum jede diefer Glocken einzeln fteht, und mit den Stielen der andern Glocken nicht zufammen hängt, die kurze Zeit ausgenommen, welche das eine der beyden Thierchen nach der Theilung braucht, um fich von dem andern ganz abzufondern. 


\section{7}

Unter dem wenigen, was ich von diefen Glocken weifs, ift diefs dasjenige, wodurch fie fich von den Glocken der Bäumchen am meiften unterfcheiden. Uebrigens kommen fie in Rückficht der Zufanmenziehungen der Stiele, der Schliefsung und der Oeffnung des Mundes, des Sichtbarwerdens und der Bewegung der Spitzen, der Erzeugung der Strudel, mit den Glocken der baumförmigen Thierchen fo vollkommen überein, dafs, wenn ich hier diefe Dinge befchreiben woll te, ich dasjenige wörtlich wiederhohlen müfste, was ich davon fction oben gefagt habe.

Uebrigens ift vom Stiele diefer Thier. chen noch zweyerley zu erinnern. Erftens ift er weit dünner, als bey den Thieren, woraus die Bäumchen beftehen, und daher das. Geflechte, das man auch hier bemerkt, weit weniger fichtbar. Zweitens fchlägt fich der Stiel bey den Zufammenziehungen nicht auf fich felbft zurück, fondern macht dann fehr viel kleine, insgefamme einander gleiche Krümmungen.

Bis jetzt habe ich vier Arten folcher Glos cken mit abgefonderten Stielen entdeckt.

Die Glocken von dex erften Art find we- 
68

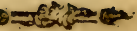

niger durchfichtig und dicker, als die anciern, und mit kleinen Bläschen oder Körnern ganz angefüllt, die mit gebrochnen Strahlen betrachtet ins Dunkle zu fallen fcheinen. Der Durchmefier ihrer Mündung ift nicht fehr vom Durchmefier der Mündung der Glöckchen verfchieden, welche fich an den Bäumchen der erften Art befinden; jedoch bey einigen ift er etwas gröfser. Ihre Actfe ift nicht länger als der Durchmefier der Mündung. Alío find diefe Glöckchen verhältnifsmälsig weit kürzer, als die Glocken der Bäumchen. Sie haben auch das Eigene, dafs fich ihr Körper nach hinten zu nicht nach und nach, fondern faft auf einmal, zufammenzieht. - Ihr Stiel ift cünf bis fechs Niahl länger, als inr Körper *).

7.

Die Glöckchen von dex zweyten Art haben viel weniger Bläschen oder Körnchen. Was die Struktur betrifft, fo nähern fie fich weit mehr, als die vorhergehenden, den Glöckchen der baumförmigen. Thierchen der exften Art; nur find fie etwas kleiner. Bey.

*) Ich habe fie mit denfelben Linfen beobacliret, deren ich mich bey den Bäumchen bedient labe 
einigen Wurzeln finde ich welche, die einen vier bis fünf Mahl längern Stiel haben, als ihr Körper ift; bey andern aber folche, deren Stiel viel kürzer ift. Uebrigens find die Glöckchen einander an Struktur, an Grölse und an allen übrigen Eigenfchaften fo vollkommen ähnlich, dafs ich, dit verfchiedene Länge des Stiels ausgenommen, nicht den gering ften Unterichied habe auffinden können. Um beide Abänderungen mit cinander vergleichen zu können, that ich in ein und daffelbe Glas zwey Meerlinfenwurzeln, wovon eine Glöckchen mit langem Stiele, die andere Glöckchen mit kurzem Stiele hatte; ich brachite. beyde fo nahe an einander, dafs in den Brennpunkt der Linfe Glöckchen von beyden KVurzeln kamen; niemals aber habe ich die einen von den andern anders, a!s durch die verfchiedene Länge ihres Stiels, unterfcheiden können. Diefs ift auch die Urfache, warum ich fie, werigftens für jetzt, nicht als zwey Arten, fondernals eine, betrachte. Jetzt zeige ich nur die Exiftenz diefer Gefchöpfe an; erft ins künftige, wemin man ihre charakteriftifchen Unterlichiede hinlänglich kennen wird, wird man fie mit Genauigkeit zu klafificiren im Stande feyn. 


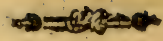

\section{8.}

Die dritte Art der Glöckchen mit einzeln ftehenden Stielen findet fich auf den Meerlinfenwurzeln viel feltener, als die zwey vorhergehenden. Statt dafs jene meiftentheils in Gefellfchaft beyfammen find, findet man diefe gewöhnlich allein. Ich habe welche in den Uhrglïfern drey bis vier Tage lang beobachtet, ohne jemals eine Theilung gewahr zu werden. Sie zichen fich zufammen, wie die andern, indem fie fich der Wurzel nähern. Ich erinnere mich nicht, ob ich Spitz hen an ihrer Mündung gef hen habe, auch finde ich es nicht in dem Tagebuche bemerkt, welches ich über meine Beobachtungen gehalten habe.

Das Glöckchen ift den Glocken der zweyten Art fehr chnlich, nur etwas kleiner. Der Stiel ift nach Verhälnnifs weit Jänger, denn er übertrifit die Glocke an Länge acht bis zehn Mahl.

\section{9.}

Die vierte Art findet fich auf denfelben Thierchen, auf welchen man auch die kleinen Polypen findet, von denen ich fchon geSpivenen habe. Diefe Glöckchen find jenen Polypen auch ähnlich; allein ftatt dafs 
jene ihre Stiele 'nicht zufammen ziehen, und an einem gemeinfchaftlichen Stamme befeftiget find, können diefe ihre Stiele zufammen ziehen, und wohnen aur den Thierchen jedes für fich. Sie haben an der Mündung Spitzchen, und erregen im Waffer gleichfalls kleine Wirbel. Sie find kleiner, als die Glöckchen der dritten Art, und ihr Stiel ift zwey bis drey Mahl länger, als ihr Körper.

Die Glöckchen mit einzeln ftehenden Stielen halten fich nicht fo lticht, wie die Glocken der Bäumchen. Es hat ganz das Anfehen, als ob fie fich in Uhrglälern nicht wohl befänden. Wenn fie eine kurze Zeit lang darin gewefen find, fo fangen fie an, ihre Stiele zu verlaffen, und herum zu fchwimmen. Zwar befeftigen fie fich hierauf von neuem, entwerler an der Meerlinfenwurzel, oder an den Wänden des Glafes; indeflen vervielfaltigen fie fich doch nicht rehr. Ihrer Theilungen ungeachtet trabe ich doch immer ihre Anzahl defto kleiner gefunden, je länger fie in den Gläfern gewefen waren. Auch das faulende Waffer ift ihnen fchädlich. Ich pflegte in ziemlich grofsen Gefilfsen die Meerlinfe, die ich aus Gräben hohlte, aufzuhebèn. 
ben. Weit feltner waren die Wurzeln mit Glöckchen alsdann bevölkert, wenn das Waffer im Gefáfse einen übeln Geruch von fich zu geben anfing:

Ob fich gleich die gedachten Glöckchen fowohl als die cben befchriebenen Bäumchen meiftentheils auf den Meeriinfenwurzeln zeigen, fo gibt es doch auch welche auf andern in dem Waffer der Gräben vegetirenden Gewächfen, fo wie auch auf andern dafelbft befindlichen Körpein.

\section{IO.}

Ich gehe nun fort zu den fchönen Räderthieren mit Futteralen *), dieich zufälliger Weife entdeckt habe, als ich die Meerlinfenwurzeln unterfuchte. Vorher hatte ich vor diefen Geichoôpfen noch keine Idee. In SPALlanzani's kleinen Schriften *\%) finde ich ein Werck von BAKER angeführt, wo von den Räderthieren weitläuftig gehandelt wird *w*). Ich weifs nicht, obBAKER. auch

*) Rotiferi ad aftuccio.

**) Opufcoli di fifica animale e vegetabile.

औ:) (HEINRICH BAKER Beyträge zu nützlichem und vergnügendem Gebrautch und Verbeferung des Micrescopiti \&c. in zwey Theilen, ans dem

Eng- 


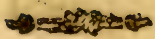

auch von diefen handelt, da ich aller Bemühungen ungeachtet jenes Werks nicht habe habhaft werden können.

Auf den Meerlinfenwurzein fieht man zuweilen getvifie Röhrchen fenkrecht ftehen; fie find eben das Futteral, worin das Thierchen wohnt. Hat man die Wurzel mit dem Futterale ins Glas gethan, fo wagt es das Thierchen nicht fogleich, das Maul *), wenn ich feinen vordern Theil fo nennen darf, aus dem Futterale zu ftecken. Es bleibt einige Zeit lang ganz im Futterale verborgen. Hierauf nihert es fich allmühlich den Rande de!lelben, und es kommen dafelbft zwey Höner zum Vorfchein, welche vorwärts ftehen; wenn das Thierchen die Organe, womit fein vorderer Theil verfehen ift, nicht ausftreckit, hingegen etwas ruickwärts zu itehen k.ommen, wenn diefelben cntwickele worden find. Nun tritt es furchtE 5

fam

Eng'ifchen ins Deuriche überfetzt. Augsburg, 375. 8. 11. Thesl, Kap. 6. S. 34S. ff. von dem Radmacher vder radformigen Thire; Kap. 7. S. 390 5. von unterfchiadlichen Gatrung̨en dor Thiere mit Rädern; Kay. 8. S. 3\$t. ff, ron Thierlein mit Schalew and Rödern.)

*) Mufo. 
fam etwas weiter vorwärts "), und fiehț fich an der Oeffnung des Futterals gleichfam $u m$, ob in diefem neuen Lande etwas zu fürch: ten fey. Es pllegt danu noch einige Zeit zu verfliefsen, bevor feine Räder zum Vorfchein kommen. Hat es diefelben zum Vorfchein gebracht, fo zieht es fie fehr fchnell zurück, und verfteckt frch wieder in das Futteral, wenn das Glas auch noch fo. wenig erfchüttert wird; allein einen Augenblick darauf zeigt es fich wieder, und entwickelt feine Räder mit weniger Furchtfamkeit, als vorher. Ich will nicht fagen, dafs diefe Rïderthiere insgefammt fo viel Vorficht brauchen; es wird gewifs unter ihnen welche geben, die weniger furchtfam find; indeffen habe ich dock diefs bey den meiften bemerkt.

Die Räder werden ron eines gewifen Membran gebildet, welche das Thier nach Willkühr bald aur diefer bald auf jener Seite ausfuannt. Wenn diefe Membran fo weit, als möglich, ausgedehnt worden ift, fo endigt fie fich in vier Bogen, fo dafs man alsdann auf dem Thiere gleichfam vier Räder, oder eigentlick vier Häften von Rädern, i wel-

*) Fig. v. 
Welche alle mitt einander kommuniciren, gewahri wird ").

Der Rand diefer Membran, der ein wenig dicker, als fiefelbit, zu feyn fcheint, hat zwey Reihen Zähne, die eine diffeits, die andere jenfeits. Es hängt von der Lage des Rades in Rückficht auf das Auge $a b$, ob man fie beyde, oder nur eine, gewvahr wird.

Ein wenig unter dem Rande bemerkt man ein fchmales Streifchen, das mit demfelben faft koncentrifch lïuft.

So bald fich diefe Räder dem Auge darftellen, fcheint es, als of fie fich faif wie die Rüder eines Bratenvenders drehen, und man glaubt auch zu fehen, nach welcher Richtung die Bewegung gefchicht; allein betrachitet man das gedachte Streifchen fowohl als die ganze Membran genau, fo wird man dafelbft nicht die geringfte Bewegung gewahr. Als ich diefe Unbereglichkeit der: Membranen bemerktt, vermuthete ich, dafs jenes Umdrehen, welches fich dem Alige beym erften Blicke darftellt, wohl eine Täufchung feyn dürfte, welche durch das Zittern gewifler Fäferchen am Rande der Räder verurfacht würde. Diefe Vermuthung

fctien

*) Fig VI. 
fchien mir um fo gegrïndeter, weil ich mich erinnerte, in Spallanzanr's Schriften gelefen zu haben, dafs man diefs bey den Räderthieren der Dachrinnen *) gewahr wird, welche diefer Naturforfcher aufmerkfam beobachtet, und vortrefflich befchrieben hat. Ich entfchlors mich daher, bey meinen Räderthieren die Zähne ihrer Räder forgfältig zu unterfuchen. Bey diefer Unterfuchung bemerkte ich bald, dais die Gefcwindigkeit, womit fie fich bewegen, nicht ganz gleichförmig zu feyn plegt, fondern von Zeit zu Zeit eine Verzögerung der Bewegung Statt findet. Ich benutzte diefe kleinen Zwifchenzeiten von langfamer Bewegung, wählte denjenigen Theil des Rades, wo ich die Zähne am deutlichften fehen konnte, und fafste einen Zahn recht ins Auge, ohne ihn je aus dem Geficht zu verlieren. Auf diefe Weife fahe ich fehr deutlich, dafs der Zahn fich auf dem Rande des Rades fort bewegte, und immer ein anderer Zahnn nachfolgte.

Weil mir ciefe Erfcheinung fehr fonderbar vorkam, fo unterfuchte ich denfelben Unfland bey vielen andern $R$ ïderthieren diefer

*) Rotiferi delle gronlaje. 


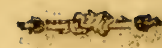

fer Art, indem ich Linfen von verfchiedener Vergröfserung brauchte, mich eines bald farkern, bald fchwächern Lichts bediente; und die Rädexthice bald mit gcbrochnen, bald mit zurück geworfuen Lichtfrahlen betrachtete. Immer ftellie fich mir diefelbe Erfcheinung dar. Daxfman fich alfo auf das deutlich fte Zeugnifs des Auges verlaffen, fo mufs man fagen, dais das Thier feine Räder. nicht hexum dreht, fondern dâs fich blos auf dem Rande derílben die zwey Reiben Zähne fort bewegen.

Inzwifchen mufs ich geftehen, dafs es in zwey Fallen das Anfehen hat, als ob eher ein Zittern von Spizchen, als eine fortfchreitende Bewegung von Zisnen Statt finde. Erftens, wenn das Thierchen feine Rüder zu entwickeln anfingt. Zweytens, wenn. zwey Räder eine folche Lage haben, dais die Zühne des einen irgendwo über die Zïhne des andern zu liegen tommen, und fich nach. der entgegen gefétzten Richtung tin drehen. Was den erften Fall betriff, fo darf man fich, da die Räder noch nicht hinlänglich entwis ckelt find, nicht wundern, dafs die Zishne noch nicht frey fpielen können, fonderr gleichfam gehemmt werden; zu gefchweigen, dafs fie alsdann einander fo natie find, dats. 


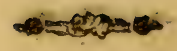

das Auge fie nicht wohl unterfchieiden, folg. lich auch ihe Bewegung nicht gut erkennen kann. In zweyten Falle mufs man, da die Zähne des einen Rades fich oben, und die Zühne des andern Rades fich zugleicher Zeit unten bewegen, und man diefe von jenen nicht wohl unterfcheiden kann, nothwendig eler ein Zittern, als eine fortfchreitende Bewegung derfelben gewahr zu werden glau* ben. Ich fehe alfo, was mich alsdann täufchen und zum Inthum verleiten kann. Stellen fich hingegen die Zähne dés Rades dem. Auge ganz deutlich dar; macht jeder derfelben im Auge cinen lebhaften Eindruck; macht es die Verzügerung ihrer Bewegung möglich, fie noch genauer zu unterfuchen: fo Geht man auf das deutlichife, dafs fie fich wirklich fort bewegen, und es läfst fich an der Wahrteit diefer Erfcheining fchlechterdings nicht zweifeln. Durch welchen Merhanismus aher wird diefe Bewegung hervorgebracht? Wie find wohl die Zatine an der Peripherie des Rades angebracht, dafs the fo darauf hingleiten können?

Nicht bey allen Räderthieren drehen fick die Zähne der Räder nach derfelben Seite: bey einigen bewegen fie fich von der linken Seite nach der rechten, bey einigen andern 
von der rechten nach der linken. Daffelbe Räderthier bewegt fie nicht immer nach einerley Richtung. Wenn die Membran um die Mündung des Thieres die vier Halbräder ordentlich darftelit, fo drehen fich die Zähne aller nach einerley Seite zu; da aber das Thier feine Räder nach Willkühr drehen und wenden kann, fo gefuchieht es fehr oft, dafs die Zähne des einen Rades nach einer Richtung hinlaufen, indels die Zähne eines andern fich nach der entgegengefetzten Richtung bewegen.

Nicht immer wird man alle vier Räder des Thieres gewahr. Es hängt von feiner Stellung und von der Richtung, in welcher. es die Rader hält, ab, ob man mehr oder weniger fieht. Da es fich aber oft bald auf eine Seite, bald auf eine andere wendet, um feine Nahrung zu fuchen, fo braucht man nur, wenn man fie alle fehen will, das Auge einige Zeit lang auf das Mikrók kop zu halien.

Etwas unterhalb der Räder lást die Durchfichtigkeit des Thieres ein gewiffes Organ erblicken, das meines Erachtens beftimmt ift, die Speifen aufzunelimen, und in ihre Behälter fortzufchaffen. Wenn fich das Thierchen mit einem Theile feines Körpers aus dem Futterale heraus begibt, ohne die Räder zu entwickeln, fo ift das gedachte Or- 
gan urbeweglich; hingegen of cillint es in Einem fort, wenn die Ruider entwickelt find. Nicht immer zeigt fich diefes Organ unter. einer und derfelben Geflalt. Zuweilen zeigen fich gleichfam zwey C, das eine gerade, dos andere umgekehrt, die etwas auf- und wiecherteigen, indem fre fich wechfelsweife ein vienig nälem, und von einander entfernen. Andre Mahle wird man eiren kugelähnlichen Kürper gervahr, der im Thiercten ein wenig auf - und niederfteigt. Noch andre Mahle endlich bemerlit man gleichfam zwey Eier, die quer durh den Kö̈per unfers Thieres gegen einander licgen, in der Mitte des Irörpers, wo fie fich berühren, etwas niecrizer find, und an den enigereng fetzten Ënden fich erheben. Diefe Maningfaligkeit der Geftali im gedachten Organe länt, wenn ich mict nicht irre, von den verfliedenen Lagen ab, in welchen fich das Thier unter den Augen des Beobachters fintiet. Ueberdiefs mufs das Rüdenthier etwas sorwäts tieten, wenn die Wand des Futterals die Ofcillation diefes Organs nicht verbergen foll. Esiuähnliches Organ, wiewchl ;on etwas rerichiedene: Gellalt, habe ich auch bey. allen andern Arten der Räcierthicre gefehen, welihe ich zubeobachen Gelegen heit gctiabt habe. 


\section{8}

Die-Rörperchen, womit fich das Thierchen nährt, werden in den Mund deffelben durch den Strudel gefthit, welchen es im Waffer mit den Zähnen feiner Räder erregt. Der gröfste Theil diefer Körperchen beweg't fich nach innen zu durch den Raum, der fich zwifchen dem Rande und dem obgedachten Streifchen findet. Es fcheint dabey befirmdend $z$ feyn, dafs, indem diefe Körperchen bey einem Rade mit den Zähnen einerley Richtung haben, diefelben beym nächften Rade in den Mund des Thieres nach einer Richtung getrieben werden, welche dexjenigen, nach der fich die Zähne bewegen, entgegengefetzt iff. Während dafs das Thierchen die Körperchen, weiche daffelbe nähren können, aufnimmit, ftöfst es diejenigen, die ihm nicht bekommen würden, mit Gewalt von fich.

Um diefs alles gehörig zu erkennen, muls man nicht nur den rechten Gred des Lir lites treffen, fondern auch Wafter netmen, das an den Körperchen; womit fich diefe Ged fchöpfe nähren, einen Ueberflu s befitzt, und, ohne zu ermüden, alles dasjenige beobarhten können, was fich zuträgt, während da? das Räderthier die Zähne jener wunderbaren Räder f́pielen läfst.

Auch diefes Räderthiex fcheint, fo wie 


\section{1}

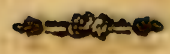

die andern Räderthiere, aus einer gallertar* tigen, fehr mannigfaltiger Biegungen fähigen Materie zu beftehen.

Das Futteral befteht aus Kügelchen, die fehr regelmäfsig zufammen gefuigt find. Jedes Kügelchen ift gleichfam der Mittelpunkt von fechs andern gleich grofsen Kügelchen. $\mathrm{Da}$ das Futteral undurchfichtig ift, fo mufs man es, um feine Zufammenfetzung recht gewahr zu werden, mit zurückgeworfenen Lichttlahlen betrachten; inzwifchen kann man am Rande die Kügelchen auch mit gebrochenem Lichte erkennen. Es ift nicht vollkommen cylindrifch; vielmehr erweitern fich feine Wände unmerklich nach oben zu.

Nicht alle Futterale enthalten ihr Thier chen. Wahrfcheinlich kommt es darin um, denn niemals habe ich bemerken können, dafs eines von den Thierchen, die ich in meinen Uhrgläfern hielt, das Futteral verlaffen hätte. Um zu fehen, ob das Thier chen fein Futteral nach Willkühr verlaffen könnte, fuchte ich es dazu mehr als einmahl zu nöthigen, indem ich das Glas neigte, fo dafs das Waffer ablaufen, und das Futteral trocken bleiben muiste. Ich hoffte, dafs das Räderthier dem Waffer zu folgen fuchen, folglich aus feiner Hülle, wenn diefs anders möglich wäre, ganz zum Vorfchein kommen würde. 


\section{3}

wiirde. Allein fo bald fich das Thierchen im Trocknen fühlte, verliefs es fein Futteral nicht nur nicht, um dem Waffer zu folgen, fondern kroch vielmehr wieder hirein, und kam gax nicht mehr zum Vorfchein.

Noch wollte ich gern wifien, ob auch diefes Räderthier die höchfft bewundernswürdige Eigenfchaft, wieder aufzuleben, befälse, welche man bey denen bemerkt hat, die fich im Sande dex Dachziegel aufhalten. Ich liefs in diefer Abficht den Waffertropfen, wo das Futteral war, abdunften. Einige Stunden hernach gofs ich wieder Waffer darauf, konnte es aber nicht dahin bringen, dafs das Thierchen den Mund wieder heraus gefteckt hätte. Weil ich wufste, dafs auch die Räderthiere der Dachziegel nicht wieder aufleben, wenn fie fich beym Verdünften des Waffers nicht unter Sandkörnchen befinden, fo wiederholte ich mehr als einmal den Verfuch mit meinen Räderthieren, indem ich, ehe ich noch das Waffer abdunften liefs, Sand vom Dache in die Gläfer, worin die Thiere waren, that ; allein diefe Vorficht war ohne allen Nutzen. Ich glaube daher, dafs die Räderthiere von diefer Art nicht wieder belebt werden können, venn fie ihr Leben ein mal verloren haben.

Als ich einft eines diefer Räderthiere beo. F 2 bach- 
84

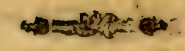

bachten wollte, fahe ich daffelbe zu meinem Erftaunen nicht vier, fondern nur zwey Rädex, oder vielmehr ein einziges, etwas längliches, in der Mitte fehr niedergedrücktes Rad, deffen Umfang nach dem Mittelpunkte des Mundes zu etwas gekrümmt war, zum Vorfchein bringen. Die Zähne deffelben waren, nicht fo häufig, und etwas dicker, folglich auch merklicher, als diejenigen, womit die vier Räder der andern verfehen find. Ich hielt dieis Gefchöpf damals für ein Monftrum feiner Art. Sie haben mich aus diefem Irrthum gezogen, als ich das Vergnügen hatte, mich bey Ihnen zu befinden. Das dieferm Gefhüpfe, von dem ich jetzt rede, vollkom1) men ähnliche Räảerthier, welches wir zufammen damals beobachteten, und Ihre Verficherung, dafs die andern von Ihnen beobachreten Räderthiere völlig eben fo befchaffen find, überzeugen mich, dafs die Räderthiere mit Futteralen, welche ich bis jetzt gefehen habe, zwey verfchiedene Familien ausmachen.

Die Art und Weife, wie fie ihr Gefchlecht fortpllanzen, ift mir ganz unbekannt. In neuern Zeiten haben Baker, SpaltanZANI, ROFFREDI entdeckt, dafs dieRäderthiere der Dachrinnen Eicr legen, und nicht, wie LeEUWENHOEK glaubte, 'lebendige verwoperas? - Junge 
Junge gebåren *); es fcheint daher daffelbe der Analogie zu Folge von unfern Räderthieren mit Futteralen zu gelten. Allein wir wiffen fchon, wie wenig den Folgerungen, die aus der Analogie der Dinge gezogen werden, zu trauen ift. Nur das Studium der Natur kann uns nach und nach in den Stand fetzen, ihre Geheimnire, fo viel als möglich, zu enthüllen. Ich verfchiebedaher mein Urtheil hierüber, bis ich Gelegenheit haben werde, durch Thatfachen zuverläfsige Kenntniffe davon einzufammeln. Indeffen geftehe ich, dafs ich in den Uhrgläfern, wo meine Räderthiere mit Futteralen waren, niemals eines von jenen eiförmigen Kösperchen habe bemerken können, welche die von den gedachten drey Naturforfchern beobachteten Räderthiere der Dachziegel von fich gegeben haben.

So weifs ich auch nicht, ob diefe Thierchen ihr Haus fich felbftzubereiten, wiefich einige Arten der Motten felbit verfertigen, oder ob es ein Werk der F

$\mathrm{Na}-$

7) (Für I.eeuwrnhoek's Meinung fehe man GoEzENS Beabachtung von dem langgefchwanzten Räderthiere, in K. BonnETs, wie auch einiges andern berïhmten Naturforfcher, auserlefenen Abhandlungen aus d:s Infik:ologie, S. $5: 3$. f., )

*) Tignuola. 
86

Natur felbft iff, das mit dem Thierchen, we ches fich darin aufhält, Ein Ganzes ausmacht. If jenes der Fall, warum hat es mir nie gliicken wollen, auf fo vielen Meerinfenwurzeln, die ich in diefer $\mathrm{Ab}_{\text {r }}$ ficht mit der gröfsten Sorgfalt unterfucht habe, ein Thierchen in dem Augenblicke, dạ es fich feine Zelle verfertigte, zu beabachten? Und warum haben diejenigen, deren Futterale ich das Wailer durch Neigung des Glafes entzog, lieber darin umkommen, als daffelbe verlaffen wollen, um in einem Elemente, das zu ihrer Exiftenz fo nöthig ift, fortzuleben? Macht hingegen das Futteral einen Theil ihres Körpers aus, wie zum Beyfpiel die Schneckenfchaale ein Theil von der Schnerke ift, wie ift es dann möglich, da diefe Thierchen immer an einer und derfelben Stelle der Meerlinfenwurzel bleiben müfsen, dafs ihre Jungen auf andern Wurzeln gefunden werden, wo die Mutter das Ei oder das Junge unmöglich hat hinlegen können?

Die gewöhnliche Länge diefer Futterale beträgt ung ef $\mathrm{it} r \frac{7}{\mathrm{~T} g}$ Linie, und der Durchmeffer der Mündung $\frac{x}{3} \frac{}{6}$ oder ein wenig darüber *).

II.

5) Man kann die Räderthiere mit Linfen von 110 bis 300 recht gut beobachter. 


\section{7}

I I.

Eine andere Art von Futteralen, die zwar kleiner, als die vorhergehenden, find, aber doch denfelben einiger Mafsen gleichen, habe ich auch auf den Meerlinfenwurzeln gefunden. Anfangs glaubte ich, dars fie denfelben Räderthieren angehörten, und der ganze Unterfchied darin beftände, dafs die Thierchen, welche fie bewohnten, noch nicht fehr gewachfen wären; allein als bald darauf das Thierchen mit einem Theile feines Körpers zum Vorfchein kam, ward ich meinen Irrthum gewahr. Es ift diefs eine ganz andere Art von Thierchen mit Futteralen, die mit den Räderthieren nichts zu thun haben. Ihr Futteral erreicht kaum ein Drittel der Länge des Futterals der Räder• thiere, und ift auch drey bis vier Mahl enger. Es ift nicht, wie das Futteral der Räderthiere, ein Aggregat zufammen gefetzter Kügelchen, fondern ganz glatt und einförmig. Die durchfichtigen Wände laffen den Bewohner fehen, der, wenn er hinein kriecht, wiegeichieht, fo oft das Waffer ein wenig bewegt wird, nur die hintere Hälfte des Futterals einnimmt. Wenn das Thier einen Theil feines Körpers herausfteckt, fo wird der Körper je Jänger, je dünner; indeffen bewegt es eine Krone von Fädchen, und indem es

$$
\text { F } 4 \text { fich }
$$


88

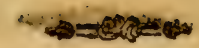

fich immer mehr verlängert, wird zuletzt das Ende ein wenig breiter, und mit einem fehr weit hervorragenden Rand umgeben *): Danin befinden firh die Fädchen um den Rand herum einzeln und zerftreut, und find des halb weit weniger fichtbar, als da das Thier fie zu bewegen angefangen hatte.

Diefes Thierchen lebt nicht fo einfam; wie das Räderthier. Ich habe manchmal zwey dergleichen Thierchen in einem und demfelben Futterale gefehen, was ich bey den Räderthieren nie habe bemerken können. Wenn in diefem Falle die zwey Einfiedler. aus ihrer gemeinfchaftlichen Zelle ein wenig. heraustreten wollen, fo veriängert fich das eine Thier etwas eher, als das andere, und immer pllegt, wenigftens fo viel ich habe bemerken können, ein und daffelbe Thier voran zu gehen. Das Thierchen, das zuerft aus dem futterale zum Vorfchein kommt, tritt auch etwas weiter heraus, als das andere: das eine fteckt feinén Körper ungefähr um die Hilfte, das andere aber nur um ein Drittel heraus. Man follte faft denken, dafs das erfte eine Art von Oberherrfchaft uber das zweyte ausuibe, und dafs das letztere nicht wagt, fich etier, als das erftere, zu Jewregen, oder eben fo weit heraus zu tre- 


\section{9}

ten. Irideflen find erft weit mehr Beobach. sungen anzuitellen, bevar man als eine charakterififche Eigenfchaft diefer Thiere anzufehen berechtigt ift, was bey den wenigen Thieren, die ich beobachtet habe, ein blofo fer Zufall hat feyn können.

Auch diefe Thierchen machen im Wef fer Strudel, um die Körperchen, wovoz fie fich nähren, anzuzichen ").

\section{2.}

Auf denfelben Meerlinfenwurzeln gibt es noch eine andre Art von Futteralen, die ron Thierchen bewohnt werden. Diefes Futteral ift noch kleiner, als dasjenige, in welchem fich die fo eben befchriebenen Thierchen befinden. Eshängt an der Wurzel vermittelft eines Stieles felt, in " elchen fich fein hinterer Theil zu endigen pflegt $\left.w^{*}\right)$. Es hat faft die Form kines etwas langen Gefáffes: an den Wurzeln des Stiels wird das Futteral nach oben zu weiter, und bildet gleicham den Bauch des Gefäfses; hierauf wird es enger, und ftellt den Hals deffelo ben dar.

Einige diefer Gefchöpfe hängen an der Meerlinfenwurzel nicht init diefem Stiele,

$$
\text { F. } 5
$$

der

. ii) Diefe und die folgenden Thierchen habe ish mit tinfeng!afern vơn 150 bis 700 beabaclutc: (5) Fig. V11!。 
99

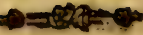

der ihnen fehlt, fondern unmittelbar mit dem hintern Theile des Gefäfses feft.

Zuweilen fteckt das. Thier durch die Mündung feines Futterals einen Theil des Körpers heraus, faft eben fo wie diejenigen, von denen ich kurz vorher gefprochen habe, Andre Mahle bleibt es ganz im Futterale ftecken, und bewegt nur feine Spitzchen.

Diefs ift alles; was ich Ihnen über diefe dritte Art von Thierchen mit Futteralen fagen kann, wenn anders zu einer und eben derfelben Art Thiere gezählt werden könren, deren einige einen Stiel, andere keinen haben, einige aus dem Gehäufe ttwas hervor treten, andere nurihre Spitzchen heraus flecken.' Es wäre noch zu unterfuchen, $o b$ diejenigen, welchen der Stiel fehlt, denfelben noch entwickeln, wie die Glöckchen thun, von denen ich fchon gefprochen habe; und ob diejenigen, welche ihre Spitzchen herausftecken, jemals auch mit dem vordern Theile ihres Körpers zum Vorfchein kommen; Unterfuchungen, die ich anzuftellen noch nicht Murse gehabt habe.

- Diefe und die vorhergehenden Futterale hängen zuweilen auch mit den Wänden der Futterale dir Räderthiere zufammen.

13.

Statt dafs die angeführten Arten der Thier- 
Thiexchen ihr ganzes Leben hindurch mit einer Meerlinfenwurzel feft zufammen hängen, gibt. es eine andere Art, welche fich davon nach Willkühr los machen kann. Das Aeufo fere diefes Thierchens befteht aus einem länglichen Gehäufe, deffen Durchmeffer von der Mitte nach beyden Enden zu abnimmt, welche einander an Geftalt und Dicke gleich find. Diefe Enden find durchlöchert *). Niemals habe ich einen Theil des Thieres durch diefelben zum Vorfchein kommen fehen. Obgleich das Gehäufe halb durchfichtig ift, fo habe ich doch niemals das Thier, welches daffelbe bewohnt, gewahr werden können. Man bemerkt darauf weiter nichts. als gewiffe der Länge nach laufende Spuren. Seine Farbe !ift röthlich gelb.

Das 'Thierchen hängt meiftens mit einem feiner Enden an der Meerlinfenwurzel feit, und zwar gewöhnlich in einer auf die. Wurzel fenkrechten Richtung. In diefer Lage ift es fo unbeweglich, dafs man es nicht für ein lebendiges Wefen halten follte. Es bleibt in derfelb n ganze Stunden, ja ganze Tage. Endlich geht es los, und fteigt in der Flüftigkeit fehr langfam auf und nieder, meittens ohne fich yon der Wurzel, mit welcher es zufammen hing, weit zu entfernen. Die an-

*) Fig. IX. 
andern Thiere (nicht einmal die Infufionsthierchen ausgenominen, bey denen der vordere Theil den hinternähnlichift, wohin die zahiricichen Arten der eyförmigen gehören) pllegen, wenn fie fchwimmen, immer einen und denfelben Theil vorwärts zu halten; wenn fie daher zurück kehren wollen, fo wenden fie ihren Körper um. Unfer Thierchen hingegen bewegt fich vor- und rückwärts, ohne fich umzuwenden; derjenige Theil, welcher, wenn es fich vorwärts bewegt, der vordere ift, wird, wenn es zurück kehrt, der hintere.

Diefes, Thierchen ift gröfser, als die vorhergehenden zwey Arten, aber kleiner, als das Räderthier n:it cien Futterale *).

Ich habe Ihnen von den Thierchen, welche fich auf der Meerlinfenwurzel aufzuhalten pflegen, nur eine kleine Anzahl angegeben. Es finden fich dafelbff noch fehr viel andere Arten von den fonderbarften Geftalten. Ich zweifle nicht, Sie werden, wenn Sie diefen Gegenftand Ihrer Aufmerkfamkeit würdigen, Gelegenheit genug finden, Ihren Scharffinn, aber auch Ihre Geduld zu üben.

Nicht

*) Ich habe es mit Linfen von xyo bis 300 b:ob. achtet. 
Nicht in allen Giäben, wo man Neerlinfen fieht, finden fich alle Arten der Thierchen, die fich auf diefern Pfänzchen aufzuhalten pllegen. Nur aus einigen habe ich baumförmige Thierchen von der erften Art, und nur aus zweyen welche von der andern Art erhalten. Glöckchen mit abgefonderten Stielen von dex erften Axt habe ich in allen Gräben gefunden, aus welchen ich viel Meerlinfen habe bekommen können; die Glöclschen von der zweyten Art finảen fich in einigen fehr häufig, allein in andern habe ich deren nicht ein einziges anretroffen. Die meiften Guäben haben mir weder Glöckchen von der dritten Art, noch Thiere von den zwey verfchiednen Arten, die ich auf gewiffen Wafferthieren gefunden habe, ob fich diefe gleich darin befanden, gegeben. Räderthiere mit Futteralen habe icti aus fehr wenig Gräben, und nux aus einem einzigen in grofser Menge erhalten. Die Thierchen mir Gehäufen, deren ich zuletzt geclacht habe, hat mir ein einziger Graben gegeben. Norh mehr: ich habe diefe Verfchiedenheit nicht nur in verfchiednen Gräben, fondern fogas in einem und eben demfelben Graben zu verfchiedenen Zeiten beobachtet. Wie oft habe ich nicht Thiere von einer der angefihrten Arten in denfelben Gräben umfonft gefuclit, 


\section{4}

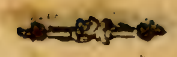

wo ich welche, und $z$ war in nicht geringer Anzahl, zehn oder vierzehn Tage vorher gefunden hatte!

Es iftZeit, diefen langen Brief zu fchliefo fen. Ich umarme Sie, mein theurer Freund, und bitte Sie, in meinem Namen Ihren gelehrten Bruder zu grïfsen, deffen Freundfchaft ich, wie die Ihrige, fchätze. Ich verharre u. f. w.

Conegliano, den Iechsten November, 17860

\section{Nachichrift.}

Diefer Brief war fchon geendigt, als ich mich entfchlofs, bey den baumförmigen Thierchen der erften Art cie Spitzchen und das Losgehen der Glöckchen von neuem zu beobachten; zwey Gegenftände, worin ich noch nicht aufs Reine gekommen war. Ich kann nicht umhin, des Refultates diefer nevien Beobachtungen hier noch mit ein Paar Worten zu gedenken.

Ich hatte fchon vermuthet, dafs die Spitzchen auch dann vorhanden find, wenn fie vom Auge des Becbact.ters nicht erkannt werden. Ietzt habe irti das Vergniigen, meine Vermuthung beffätigt zo fet en. Ich bin nun dasjenige gewahr gew orden *), was mir

*) Mir den Linfen 250 und 300 . 
bey meiner frühern Unterfuchung entwifcht war. Nach der Zufammenziehung ftecken die Glocken, indern fre die Mündung wie der öfnen, ihre zahlreichen Spitzchen hero aus, die fie, als fie die Miindung fchloffen, einwărts gekehrt, und in ihrer Höhlung verfchlofen hatten. Sie drehen fie in diefem Augenblicke von der innern Seite des Randes nach der äufsern zu. Indefs die Spitzchen fich fo drehen, find fie fehr fichtbar. Kommen fie aber nach aufsen hin, fo zerftreuen fie fich, und entziehen fich dadurch dem Geb fichte. Ich habe daher ihr Sichtbarwerden und Verfchwinden ganz richitig erklärt, als ich es, einer blofsen Muthmafsung zu Folge, von der grofsen Feinheit und Durchfichtigkeit derfelben herleitete; und die Einwendung, die ich mir machte, dafs die Spitzchen, wenn die Mündung gefohloffen ift, alle zufammen vereinigt feyn, folglich am deutlichften in die Augen fallen müfsten, verfchwindet nun ganz, denn wir wiffen nun, dafs die Thierchen diefelben, wenn fie fie beym Verfchliefsen der Mündung einwärts beugen, inwendig in den Lippen verbergen. Was das Losgehen der Glocken betrift, fo bemerke ich hiernoch einige Unftände, die mir vorher entgangen waren. Bevor das Thierchen die Mündung fchliefst, zeigt fich 
um daffelbe eine dünne Schnur ein wenig iiber demStiele، Dann fängt es an, dieLip pen halb zu verfchliefsen, und die Fädchen um die Schnur herum fehr langfam zú bewegen. Die Mündung verfchliefst fich immer mehr; das Thierchen zieht fich zufammeny und es erfolgt, was ich bereits bemerkt habe; als ich rom Losgehen deffelben handelte. If dafielbe los gegangen, fo bewegt es. fich jehr heftig. Die Bewegung der Fädchen dauert mit folcherSchnelligkeit fort, dafs man Tie kaum unterfcheiden kann. Norh hat es die Geftalt eines Eimers nicht; der Theil, wo fich die l ädchen befinden, befizt nun mehr den gröfsten Umfang, aber ift noch micht offen; es beteckt itm eine Art von einer etwas konvexen Membran. Was wird hernach aus diefer Membran? Wie bildet fich die neue Mündung des Thieres? Diefe Fragen kann ich jetet noch nicht beantworten. Um darauf befriedigend zu antworten, mürste man das Thierchen fo lange beobachten, bis es die Glockengeftalt wieder amimmt. Darciber verfliefsen aber viel Stunden, und fo lange hält es das Auge unmöglich aus; za gefchweigen, dals das Thierchen, indern es fich hin und her dreht, fehr oft das ganze Feld des Mikrofkops durchläuft, und fich aus dern Gefichte yerliert. 


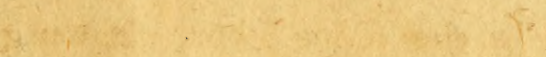

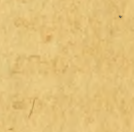

ingotisise

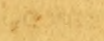

ing

$\ln ^{2}+406$

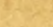

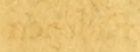

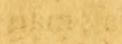

$(2+3)=2$

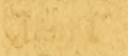

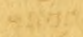

afy

$\therefore 30 y+304$

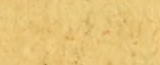

i. 35 is 8302

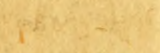

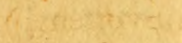

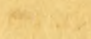

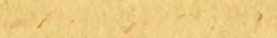
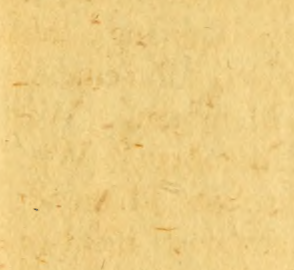

(2) 1

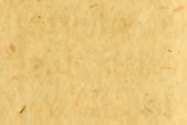

$435 \times 3 \times 24=$

18

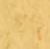

$\therefore$

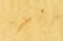

19.

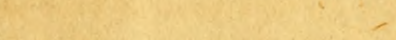


s?

in है
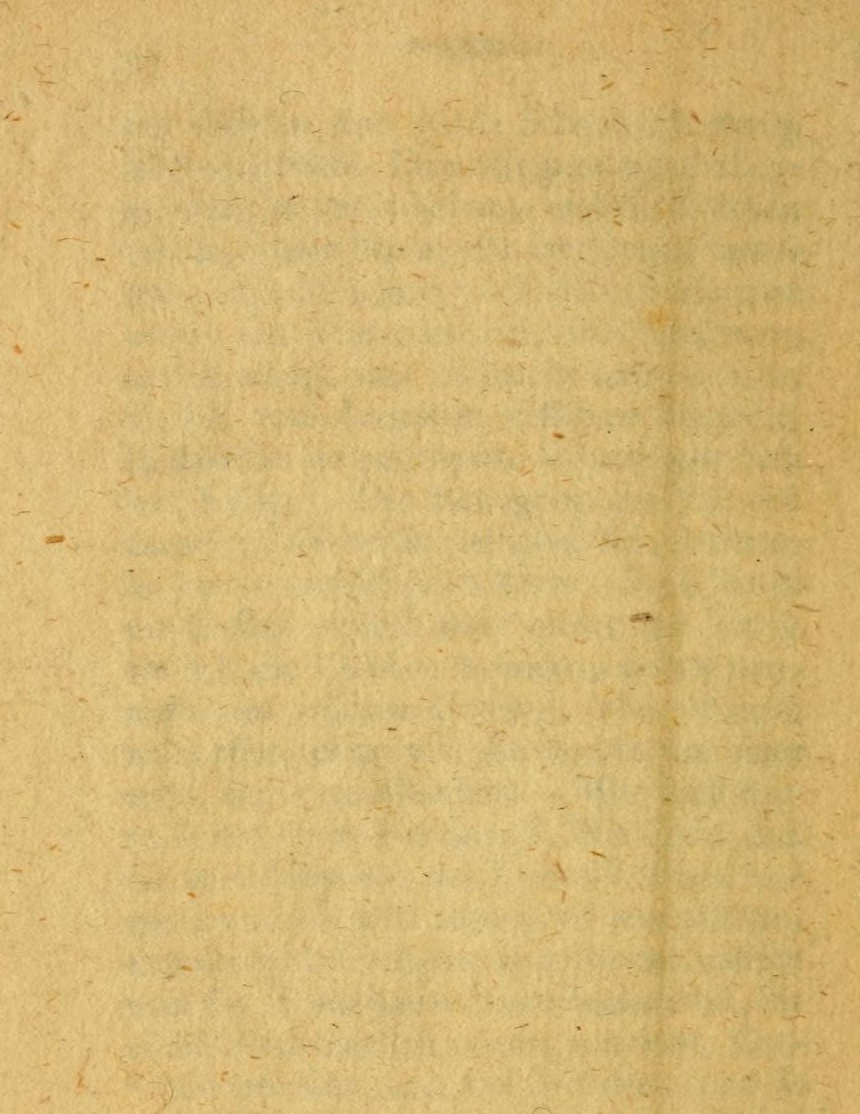

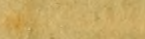

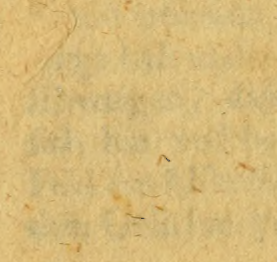

(2)

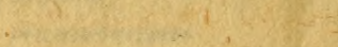


2
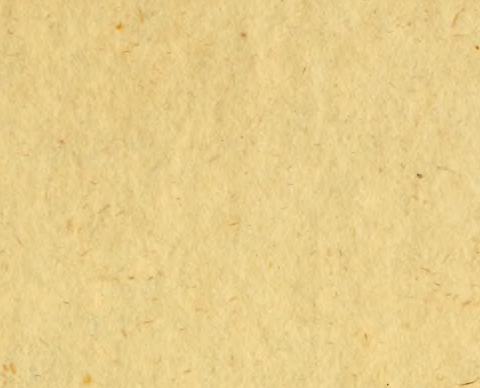

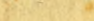

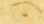

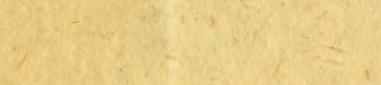

89

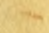

$-1$

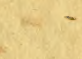

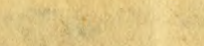




\section{5}

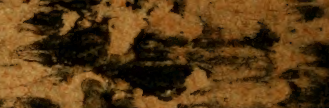

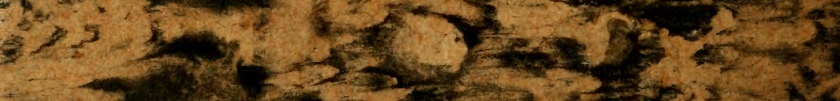

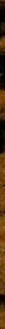

$x^{2}=-2+x^{2}-4$

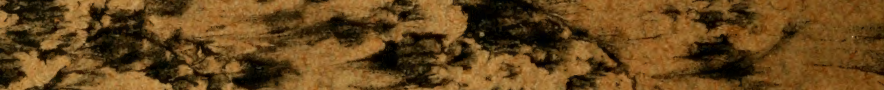

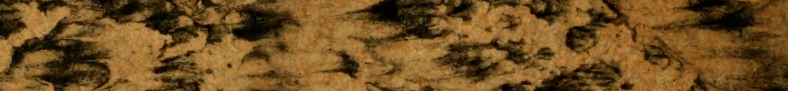

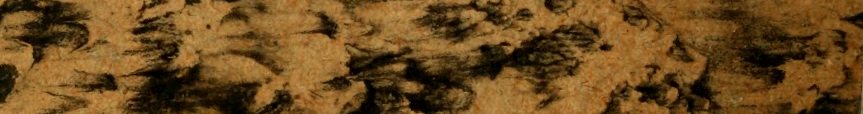

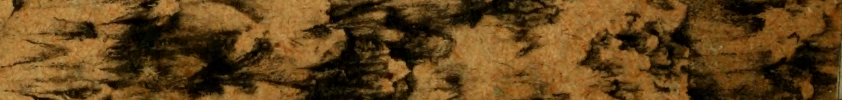
$x^{3}-3 x^{2}+y^{2}$ $35+4 x^{2}-5$

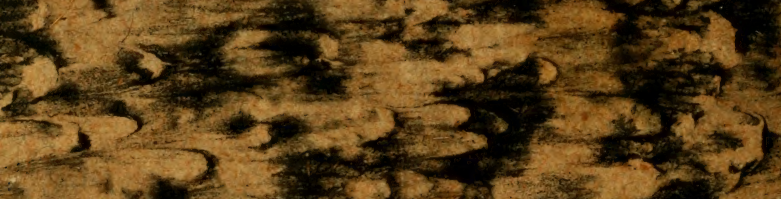

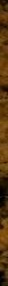

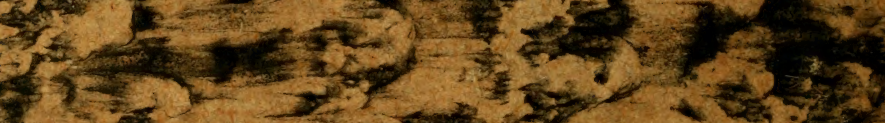

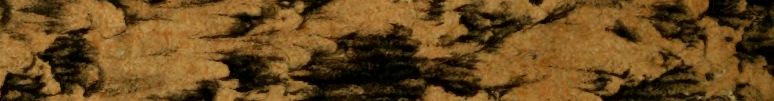

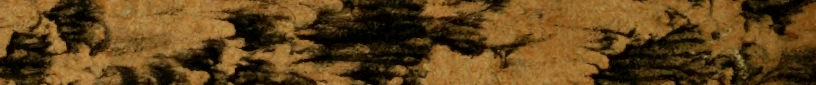

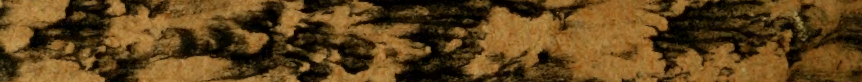

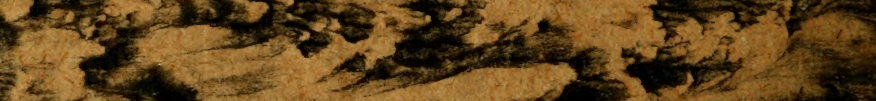
is $5,=25$

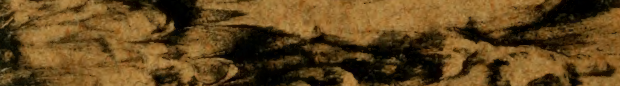

